Hin 2.

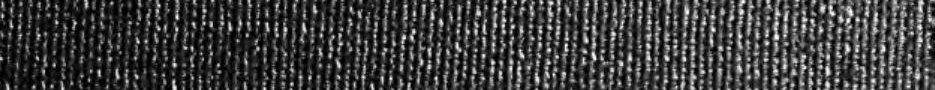

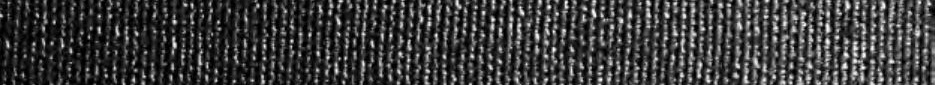

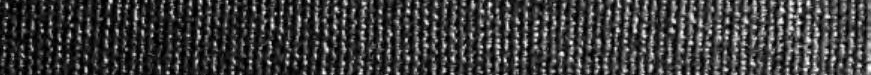
64.

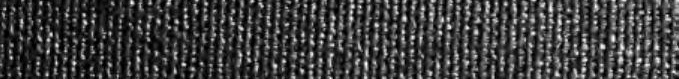

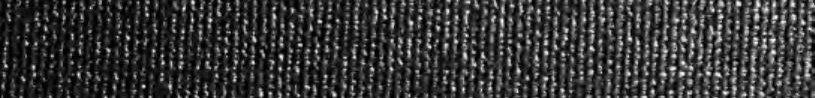
(3.

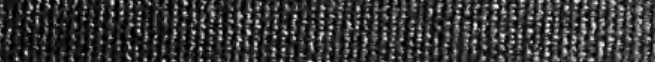

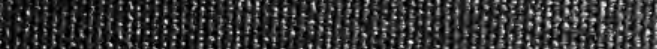
(4)

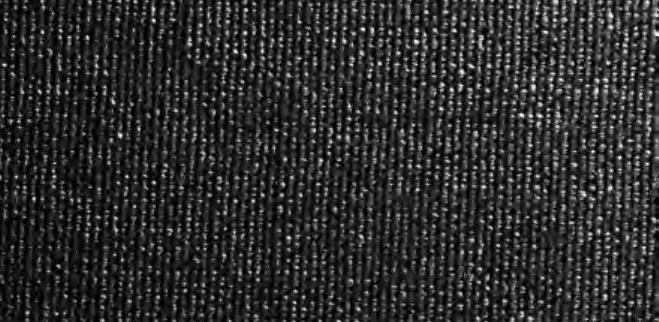

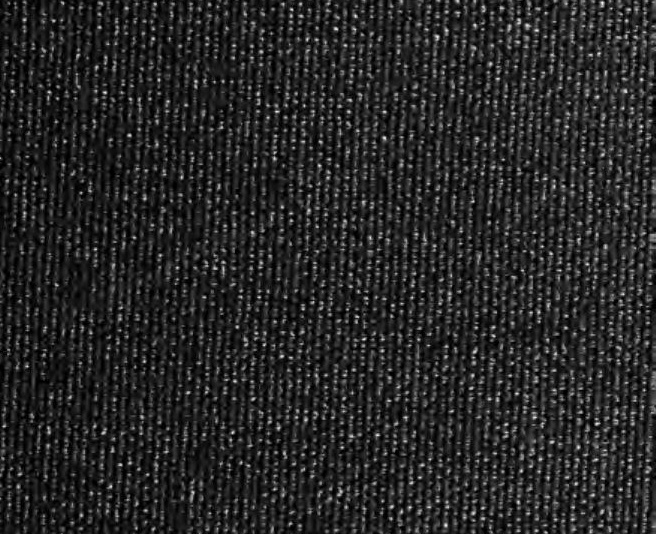
Whathom (3)

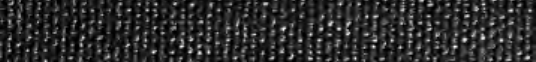
Wham WWHW

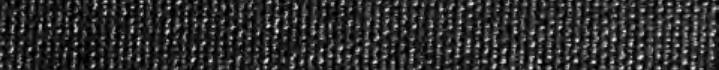
W. 1 m Hom 2.

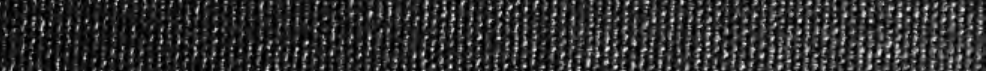
6.1.2.

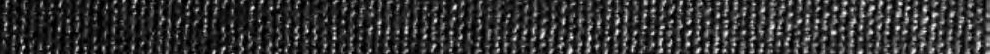

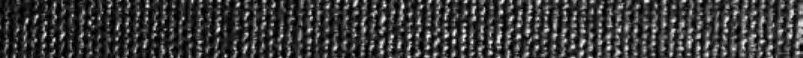

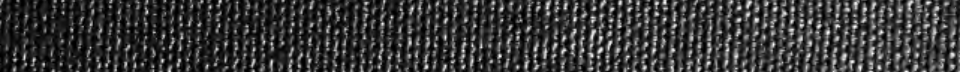
16010.6.

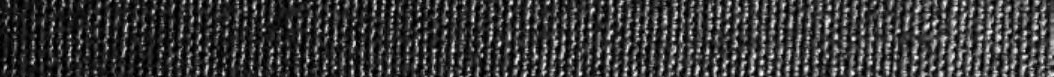
W. 3.

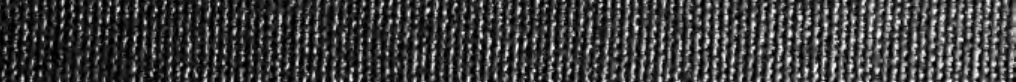

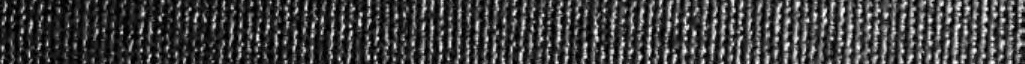


Digitized by the Internet Archive in 2007 with funding from Microsoft Corporation 




\section{The Coefficient of Safety in Navigation}

BY PROF. W. A. ROGERS,

OF CAMBRIDGE (U. S.) OBSERVATORY.

AND COMMANDER P. F. HARRINGTON, U. S. N.

1882.

[Reprinted from the Proceedings of the U. S. Naval Institute, Vol. VII, No. 4.] 



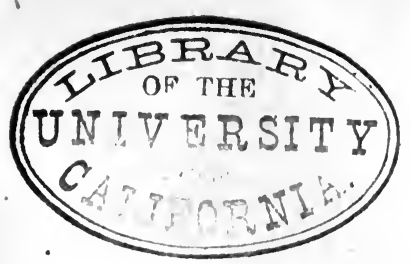

\section{THE PROCEEDINGS}

OF THE

\section{United States Navaj Institute.}

Vol. VII. No. 3.

1881.

Whole No. 17.

NA VAL I NS'I I U TE, A N NAPOLIS, M D.

JANUARY 28, 1881.

Lieut. Commander P. F. Harrington, U. S. N., in the Chair.

\section{THE COEFFICIEN'T OF SAFETY IN NAVIGA'TION.}

By Prof. W. A. Rogers, of Cambridge (U. S.) Observatory.

It is customary among engineers and architects, in making allowance for the strain to be borne by any part of a structure, to assign to the materials used a strength sufficient to withstand a strain much greater than that to which the structure is ever likely to be subjected. By a combination of theory and experiment it can be found, for example, what is the breaking load of a wooden or iron beam of given dimensions, and from the empirical law thus established we can ascertain approximately the breaking load for any beam of the same material and having the same form and dimensions; but in order to cover all possible differences which may exist among different beams, a coefficient of safety is either introduced into the formula representing the breaking load, or is applied to the result obtained from the formula. This coefficient should be large enough to cover not only the largest possible deviation between theory and experiment, but also to meet all unforeseen emergencies, such as time and age inevitably bring.

Passing now to the consideration of the term coefficient of safety as applied to navigation, it is our object to find the limits within which, under ordinary circumstances, a vessel can be located at sea, 
and then to adduce some considerations which will enable us to form an intelligent judgment in regard to the range of error to which observations are liable. The quantity wanted is the average number of miles of error in latitude and longitude which we may fairly charge upon a single observation at sea under ordinary circumstances. We have then to find the coefficient by which this number must be multiplied in order to secure absolute safety, as far as safety depends upon human means and exertions. If we represent the average error by $E$, and the safety coefficient by $P$, then $E \times P$ should cover not only the range of error to which observations at sea are liable, but also those extreme cases in which a combination of causes acting in the same direction may produce errors of greater magnitude than the most prudent navigator would even suspect. We start with the average error $E$, in a given series of observations. It is obvious that the absolute error may be as small as the least value of the series and as large as the greatest value. A constant error may also be involved in every observation of the series, even when there are no indications of its existence. The total error therefore may be:

\section{$E \times P+$ a constant.}

In this investigation the computed value of the coefficient $P$ is obtained by dividing the difference between the greatest and the least values of a given series representing errors of observation by the average value.

Capt. Williams of the ill-fated Atlantic is represented by a reporter of the New York Tribune to have said that he knew the position of his ship within her length, at the time of his last observation, twelve hours before she became a wreck. If he really made that statement, no other evidence is needed of his utter unfitness for the position which he occupied. After twelve hours' run his error was twelve miles. Was that so large an error as to justify the charges with which the daily press teemed, that he had "blundered in his calculations": In the court of investigation which followed the disaster, was the question how far it might have been allowable for him to have been in error, raised? Did the daily press raise this question? Was the question ever considered in any court of inquiry? Not as far as I can ascertain. Was this aspect of the question ever investigated at all upon any intelligent basis? If it has been, I have failed to find a record of it, after the most diligent search. In no one of 
the forty-three volumes of the English Nantical Magazine, a standard authority, to which I am largely indebted in this discussion, can I find the question once raised, and I think there are few articles bearing upon the subject of wrecks which I have not consulted. In the British Admiralty laws on this subject, especially in the new code adopted in 1849, after the repeal of what is known as Huskinson's law, almost every aspect of the question is considered except this. 'There are regulations upon almost every conceivable point, from the constitution of courts of inquiry to the furnishing of proper lime-juice for seamen. In the Wreck Register, published annually by the British Board of Trade, to which I am largely indebted for data, not only the number, but the causes of wrecks are enumerated. A small number are attributed to the incapacity of masters, but even here there seems to have been so far no inquiry as to what constitutes incapacity in this respect. If it is a fact that navigators proceed upon the supposition that they can with certainty obtain their position by astronomical observations within one mile, to say nothing of three hundred feet, the wonder is, not that so many wrecks occur, but that more do not occur. I have said I could find no mention of this aspect of the question. Perhaps I ought to except two editorials on the loss of the City of Washington. The New York Times said: "It is believed that the captain of an ocean steamer, freighted with a priceless cargo of human life, should know at all times, in spite of fog and tempest, just where he is." To which the New York World replies, that "any one who believes such stuff as this is an idiot, and that the only way for him to find ont anything about the Nova Scotia coast would be by taking command of a ship freighted, not with a priceless cargo of human life, but with a crew of cheap and congenial idiots, and required to know in spite of fog and tempest just where he was." One might almost say that the 19th century is behind the 18th in a proper appreciation of the importance of the true solution of this problem. As early as 1598, Spain offered a reward of 1000 crowns for the discovery of a correct method of finding the longitude at sea. The States of Holland, at an early date, offered a reward of 100,000 florins, and France a reward of 100,000 livres. In 1714 the British government offered a reward of $£ 10,000$ to any one who should discover a method of finding the longitude at sea within sixty miles, $£ 15,000$ within forty-five miles, and $£ 20,000$ if within thirty miles. This offer did much to awaken interest in the subject. Though we have long 
since passed the lowest limit then mentioned, thirty miles, it is doubtful if any two navigators will agree as to what limi we have actually reached. 'The general testimony of sea-captains in answer to my inquiries upon this point, is that one mile is the ordinary limit within which the co-ordinates of a ship's place can be determined. A few placed the limit at half a mile. Only one man placed the limit at five miles. He had had an experience of thirty-six years, and was considered a man of excellent judgment. For myself, I have great respect for his judgment.

I now propose to show that this is not an idle inquiry. The number of steam and sailing vessels belonging to the United Kingdom of England, Ireland and Scotland is about 25,000. The number belonging to the United States is at the present time about 22,000. These numbers vary from year to year with the conditions of trade and with the laws of supply and demand. A certain proportion are annually wrecked, either wholly or partially, the actual number for any given year varying to a certain extent with the total number of vessels, but being largely dependent upon the violence of the storms occurring during that year. But in a given series of years the average of the conditions of the latter class under which wrecks occur must be nearly the same, and the number of wrecks ought to be nearly proportional. to the total number of vessels, under average conditions of carefulness in navigation. It is therefore essential to our investigation to inquire whether the ratio of the number of wrecks to the total number of vessels in a given series of years is an increasing or a decreasing ratio.

The following data are, for Great Britain, derived from the returns to the British Board of Trade, under the title of Wrecks and Casnalties, and for the United States from the reports of the U.S. Life Saving Service. Inasmuch as the question of collisions does not necessarily come within the scope of the present investigation, the number of wrecks and casualties are given both including and excluding collisions. 


\section{Great Britain.}

$\begin{array}{cccccc}\text { Year. } & \begin{array}{c}\text { No. Vessels } \\ \text { (Steam and Sailing). }\end{array} & \begin{array}{c}\text { Total } \\ \text { Tonnage. }\end{array} & \begin{array}{c}\text { No. of Wrecks } \\ \text { including } \\ \text { Collisions. }\end{array} & \begin{array}{c}\text { No. of } \\ \text { Collisions. }\end{array} & \begin{array}{c}\text { No. of Wrecks } \\ \text { excluding } \\ \text { Collisions. }\end{array} \\ 1856 & 25335 & 4304460 & 1153 & 316 & 837 \\ 1857 & 26219 & 4491377 & 1143 & 277 & 866 \\ 1858 & 26658 & 4587993 & 1170 & 301 & 869 \\ 1859 & 26804 & 4591250 & 1416 & 349 & 1067 \\ 1860 & 26764 & 4586742 & 1379 & 298 & 1081 \\ 1861 & 27142 & 4735491 & 1494 & 323 & 1171 \\ 1862 & 27525 & 4860191 & 1488 & 338 & 1150 \\ 1863 & 27750 & 5251757 & 1664 & 331 & 1333 \\ 1864 & 27737 & 5542878 & 1390 & 351 & 1039 \\ 1865 & 27868 & 5666873 & 1656 & 354 & 1302 \\ 1866 & 28072 & 5692010 & 1860 & 422 & 1438 \\ 1867 & 27913 & 5670350 & 2090 & 414 & 1676 \\ 1868 & 27635 & 5698774 & 1747 & 379 & 1368 \\ 1869 & 26389 & 5634727 & 2114 & 461 & 1653 \\ 1870 & 25643 & 5617693 & 1502 & 361 & 1141 \\ 1871 & 25188 & 5622660 & 1575 & 351 & 1224 \\ 1872 & 25093 & 5681963 & 1958 & 409 & 1549 \\ 1873 & 24873 & 5736368 & 1803 & 381 & 1422\end{array}$

\section{UNited States.}

$\begin{array}{llllll}1873-4 & \ldots \ldots & \ldots \ldots & 1060 & \ldots & \ldots \\ 1874-5 & \ldots \ldots & \ldots \ldots & 1610 & \ldots & \ldots \\ 1875-6 & 22577 & \ldots \ldots & 2097 & 576 & 1521 \\ 1876-7 & 22476 & \ldots \ldots & 1935 & 521 & 1414 \\ 1877-8 & 21995 & \ldots \ldots & 1816 & 545 & 1271 \\ 1878-9 & 21611 & \ldots \ldots & 1953 & 568 & 1385\end{array}$

It is at once apparent from the returns for Great Britain that with a decrease in the number of vessels we have an increase in the number of wrecks and casualties. Comparing the data for the first half of the series with the data for the second half we have the following:

$\begin{array}{cc}\begin{array}{c}\text { Limiting } \\ \text { Dates. }\end{array} & \begin{array}{c}\text { Average } \\ \text { No. of Vessels. }\end{array} \\ 1856-64 & 26882 \\ 1865-73 & 26520\end{array}$

$\begin{array}{lccc}\text { Average } & \begin{array}{c}\text { Average No. of } \\ \text { Wrecks in- } \\ \text { Tonnage. }\end{array} & \begin{array}{c}\text { Average } \\ \text { Noding Collisions. } \\ \text { Collisions. cluding Collisions. }\end{array} & \begin{array}{c}\text { Average No. of } \\ \text { Wrecks ex }\end{array} \\ 4772449 & 1366 & 320 & 1046 \\ 5669046 & 1812 & 393 & 1419\end{array}$

Decrease in the number of vessels, 1 per cent.

Increase in the total tonnage, 19 per cent.

Increase in the number of wrecks including collisions, 33 per cent. Increase in the number of collisions, 23 per cent.

Increase in the number of wrecks excluding collisions, 36 per cent. 
The percentage of decrease for the number of vessels should really be considerably greater than appears from the table, since previous to 1865 the enumeration was limited to vessels of eight tons, while after 1865 all vessels of three tons and upwards were placed upon the register.

In the returns for the United States, the numbers for 1873-4 and $18 \% 4-5$ are undoubtedly too small, as no adequate means were employed for collecting the data till after the congressional act of 1874 . For the four years for which we have reliable data, the average number of wrecks excluding collisions is 1398 , which in proportion to the number of vessels is somewhat less than the number for Great Britain during the years $1865-73$.

Comparing the number of collisions which occurred in Great Britain with the number which occurred in the United States we find:

In Great Britain the ratio to the number of vessels is as 1 to 67.

In the United States the ratio to the number of vessels is as 1 to 43 .

Since in a large number of cases the arerage of all the causes, except carelessness, which produce collisions must be a constant, the modulus of carelessness as between Great Britain and the United States may be stated to be as nearly as 2 to 3 in favor of the United States.

These comparisons seem to justify a new discussion of the whole problem of wrecks and their causes. The arrangements for collecting data respecting wrecks, under the auspices of the British Board of Trade, have been constantly improved since their inanguration in 1855. In the United States the improvement in this respect since the organization of the Life Saving Service in 18\%1, and especially since the more complete organization in 1875 , is signally marked. In both countries, especially in Great Britain, the rules for the examination of both inferior and superior officers are rigidly enforced. . In no other countries are courts of inquiry upon disasters more surely held or more thoroughly condncted, and yet with all these precautions it is almost certain that the average number of wrecks in any given series of years will exceed those for the same number of preceding years, the number of vessels remaining the same. It is hardly probable that unknown or unsuspected elements enter into this problem. It is possible, however, that the limits of official investigation may be enlarged with great advantage.

I shall presently attempt to ascertain the ratio of wrecks which occur from preventable causes. If I were asked to name the one cause 
which, next to positive negligence, produced the largest number of wrecks of this class, I should say, over-conficlence. This excess of confidence is, in general, inversely proportional to the intelligence of the navigator. Of course, a successful sea-captain must rely upon his judgment; but the inevitable tendency of many years of service, with almost every possible form of experience, is to convince him that his judgment is rarely in error. Especially is this the case in too positive forecasts of the weather, in the accuracy of his observations for position at sea, and in the performance of his chronometer. Of course he places the utmost confidence in the accuracy of all data derived from the Nautical Almanac. I shall presently show that even here this confidence is not justified. In 1860, Professor Main, in his address before the Royal Astronomical Society, said, “Hansen's Tables (of the moon) are practically perfect for all the purposes of navigation, and the great nautical problem of finding the longitude at sea is now completely solved." Is it not possible that assertions like this inspire a confidence which may be the cause of more wrecks than has been hitherto supposed? Is it a fact that the problem is completely solved? I assert distinctly that it is not. I know of no more mischievous and misleading statement than this by Mr. Main, unless it be that of our own countryman, Lieut. Maury, on the performance of the chronometers used in the Grinnel Arctic Exploring Expedition. In a letter to the makers, he says, "The instruments have been subjected to the severest tests to which it is possible to subject instruments of such delicate construction, yet so exquisitely were they provided with adjustments and compensations for the very great extreme of temperature to which they were subjected, that one of them, No. 114, Loseby, after having suffered all sorts of exposure to which such instruments are liable in a polar winter, is returned with a change in its daily rate during seventeen months of only .03 s." (Signed) M. F. Maury.

This may be called a first-class recommendation, and this endorsement being good by inference for all of Mr. Loseby's chronometers, purchasers are led to suppose that they are as near perfection as human skill can make them. By reference to the report of the annual trial of chronometers at the Greenwich observatory it appears that while Loseby made some very excellent chronometers, he made also some very poor ones. I think I am safe in saying that this is the experience with chronometers of every first-class maker. 
Let us now see what is the actual state of the official inquiries into the causes of wrecks. By the Merchant's Shipping Act of 1854, it is assumed in the preliminary courts of inquiry, testimony which is held valid in Admiralty courts, that a vessel may be lost :

(a) By the act of God, e. g. being injured or destroyed by lightning, unavoidable perils of the sea, \&c.

(b) By collision.

(c) By error of judgment, incompetency of master, or officers, or pilots.

(d) By bursting of boilers, breaking machinery, \&c.

(e) By the removal of buoys, beacons, \&c.

$(f)$ By direct and wilful casting away.

$(g)$. By inattention to necessary repairs.

(h) By defective charts.

(i) By not providing proper apparel and equipments for officers and crew.

( $j$ ) By improper loading or stowage.

(k) By neglect of regulations for preventing collisions.

(l) By employing a vessel in a trade for which she is unfit.

$(m)$ By act of the Queen's enemies.

The nautical literature of this period is full of additional causes and remedies. The most important of these are:

(in) Failure to get the latitude.

(o) Failure to heave the lead.

$(p)$ Unexpected deviation of compass.

One writer adds with a grain of truth, two other causes:

$(q)$ A dead-and-alive set-no devil on board.

( $r$ ) Discord of dissension-the devil let loose.

An examination of the special and official inquiries into wrecks and casualties, and their causes, will show that the findings are based on one or more of these causes.

As an illustration, it appears from the Wreck Register for 1869 that there were during that year ninety-seven trials with the following results :

No. Cases

Acquittal from blame

Censures . . . . . . . . .

Certificates cancelled, (drunkenness) . . . $\quad$. 3

Certificate suspended, 5 years $\quad$. $\quad . \quad$. $\quad 1$ 
Certificate suspended, 18 months . $\quad$. $\quad$. 2

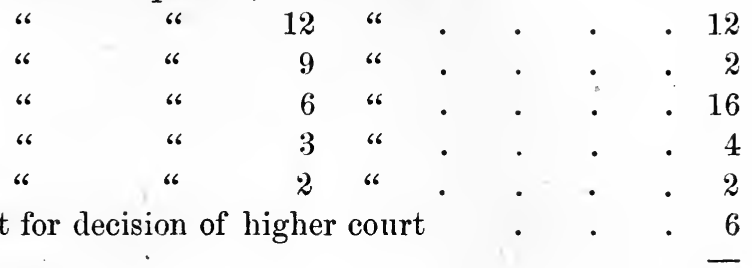

Total . $\overline{97}$

It is my purpese in this investigation to examine only those cases of wrecks which in a measure seem to have escaped attention in official investigations. They are-

I. Wrecks which occur from preventable causes.

II. Wrecks resulting directly or indirectly from over-insurance. III. Wrecks caused by the deviation of the compass. IV. Wrecks caused by errors of observation at sea.

In attempting to distinguish between the causes of wrecks, one is compelled to acknowledge at the outset that the statistics reveal certain facts which in the present state of our knowledge are very difficult to explain. Apparently the most feasible way of ascertaining what proportion of wrecks occur from preventable causes, is to account for those which occur from all other causes which can be clearly assigned, and after making proper allowance for unknown causes, to place the balance in this class. But this cannot be safely done till further investigations are made with respect to certain facts which are revealed by the statistics already accumulated. These may be stated as follows:

(a) The number of wrecks involving total loss is nearly proportional to the total number of vessels, while the number of wrecks involving partial loss shows a steady increase from year to year. This will appear from the following table.

Wrecks other than Collisions in the United Kingdom.

\begin{tabular}{|c|c|c|c|c|c|}
\hline $\begin{array}{l}\text { Year. } \\
1856\end{array}$ & $\begin{array}{c}\text { Total Loss. } \\
386\end{array}$ & $\begin{array}{c}\text { Partial Loss. } \\
469\end{array}$ & $\begin{array}{l}\text { Year. } \\
186 \%\end{array}$ & $\begin{array}{c}\text { Total Loss. } \\
3566\end{array}$ & $\begin{array}{c}\text { Partial Loss } \\
1020\end{array}$ \\
\hline 1857 & 384 & 482 & 1868 & 527 & $\$ 41$ \\
\hline 1858 & 351 & 515 & 1869 & 606 & 1047 \\
\hline 1859 & $52 \%$ & 540 & $18 \%$ & 411 & 730 \\
\hline 1860 & 476 & 605 & 1871 & 398 & 826 \\
\hline 1861 & 513 & 658 & 1872 & 439 & 1110 \\
\hline 1862 & 455 & 695 & Jan. to June & & \\
\hline 1863 & 503 & 830 & 1873 & 212 & 522 \\
\hline 1864 & $386^{\circ}$ & 653 & June to June & 316 & $10 \mathrm{arc}$ \\
\hline 1866 & 470 & 832 & $1873-4$ & & 1070 \\
\hline
\end{tabular}


(b) The increase in the number of wrecks outside of the "At Home" limits is proportionately much larger than within those limits. The "At Home"limits "embrace the cases which happen in waters within 10 miles from the shores of the United Kingdom; in waters within any bays or estuaries; in waters around any outlying sand-banks which are dry at low water; in the seas between Great Britain and Ireland; and between Orkney and Shetland and Western Islands and the mainland of Scotland." Returns of this class began with 186\%. I extract from the returns for 1873-4 the following significant numbers for British vessels only.

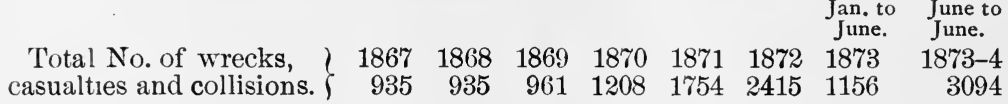

These numbers include vessels belonging to the British possessions, but the total numbers belonging to this class follow nearly the same law as those which are referred to the United Kingdom; $i$. e. there is a steady increase till about 1866 , and after that a steady decrease till 1874.

(c) Over one-half of the total number of wrecks occur when the wind blows less than a fresh gale, or "when a ship if properly found, manned and navigated can keep the sea with safety." The following table furnishes conclusive evidence on this point. It is taken from the Wreck Register for $18 \% 5$.

Wrecks Classified according to the Force of the Wind.

\begin{tabular}{r|r|rr|r|r|r|r|r|r|r|l}
\hline 1864 & 1865 & 1866 & 1867 & 1868 & 1869 & 1870 & 1871 & 1872 & 1873 & & \\
-65 & -66 & -67 & -68 & -69 & -70 & -71 & -72 & -73 & -74 & Total. \\
\hline 23 & 19 & 12 & 15 & 16 & 25 & 33 & 31 & 26 & 29 & 229 & \\
18 & 26 & 27 & 22 & 31 & 32 & 57 & 42 & 57 & 48 & 360 & Calm. \\
92 & 95 & 65 & 61 & 93 & 115 & 115 & 109 & 136 & 129 & 1010 & Light air. \\
23 & 19 & 31 & 35 & 25 & 37 & 50 & 52 & 65 & 68 & 405 & Gentle breeze. \\
149 & 150 & 176 & 150 & 157 & 162 & 161 & 198 & 175 & 211 & 1689 & Moderate breeze. \\
210 & 228 & 228 & 199 & 185 & 208 & 180 & 213 & 248 & 234 & 2131 & Fresh breeze. \\
175 & 187 & 230 & 196 & 250 & 205 & 234 & 255 & 312 & 283 & 2329 & Strong breeze. \\
46 & 52 & 97 & 59 & 78 & 50 & 80 & 95 & 197 & 165 & 919 & Moderate gale. \\
49 & 77 & 88 & 120 & 54 & 61 & 87 & 96 & 240 & 149 & 1020 & Fresh gale. \\
414 & 605 & 617 & 417 & 629 & 515 & 336 & 234 & 348 & 205 & 4320 & Strong gale. \\
211 & 157 & 204 & 310 & 139 & 186 & 182 & 126 & 246 & 160 & 1921 & Whole gale. \\
37 & 46 & 28 & 62 & 29 & 34 & 29 & 21 & 56 & 31 & 373 & Storm. \\
49 & 173 & 61 & 72 & 89 & 93 & 38 & 26 & 38 & 27 & 666 & Hurricane. \\
9 & 2 & 1 & 2 & - & -5 & 5 & 8 & 8 & 22 & 57 & Variable. \\
59 & 73 & 72 & 77 & 97 & 91 & 61 & 15 & 52 & 42 & 639 & Unknown. \\
& & & & & & & & & & & \\
\hline
\end{tabular}

(d) The number of wrecks is proportionately larger for new vessels than for those which have reached the average age of service. 
Data :

For Great Britain.

\begin{tabular}{|c|c|c|c|c|c|c|c|c|c|c|c|}
\hline $\begin{array}{c}\text { Age, } \\
\text { Limiting } \\
\text { Years. }\end{array}$ & 1865 & 1866 & 1867 & 1868 & 1869 & 1870 & 1871 & 1872 & $\begin{array}{l}\text { Jan. to } \\
\text { June, } \\
1873\end{array}$ & $187: 3-4$ & Total. \\
\hline & & & & & & & & & & & - \\
\hline $0-3$ & 151 & 277 & 209 & 176 & 198 & 130 & 155 & 211 & 94 & 182 & 1733 \\
\hline $3-7$ & 260 & 280 & 322 & 297 & 406 & 307 & 302 & 374 & 209 & 354 & 3111 \\
\hline $8-10$ & 203 & 221 & 238 & 152 & 218 & 148 & 163 & 239 & 127 & 254 & 1963 \\
\hline $11-14$ & 173 & 198 & 262 & 268 & 308 & 218 & 198 & 242 & 136 & 227 & 2230 \\
\hline $15-20$ & 269 & 289 & 306 & 270 & 314 & 246 & 243 & 322 & 170 & 318 & 2747 \\
\hline $21-30$ & 352 & 419 & 441 & 383 & 436 & 272 & 311 & 344 & 163 & 297 & 3418 \\
\hline $31-40$ & 145 & 174 & 209 & 167 & 229 & 143 & 184 & 212 & 118 & 221 & 1802 \\
\hline $41-50$ & 84 & 87 & 118 & 100 & 112 & 63 & 81 & 86 & 61 & 81 & 873 \\
\hline $51-60$ & 51 & 53 & 60 & 35 & 53 & 49 & 44 & 47 & 19 & 41 & 452 \\
\hline & 20 & 25 & 36 & 28 & 18 & 20 & 19 & 24 & 13 & 13 & 216 \\
\hline $71-80$ & 9 & 13 & 9 & 9 & 9 & 4 & 6 & 17 & 8 & 6 & 90 \\
\hline $81-90$ & $\mathbf{5}$ & 5 & 3 & 8 & 5 & 5 & 8 & 4 & 2 & 5 & 50 \\
\hline $91-100$ & & 2 & 1 & .. & 2 & $\because$ & $\because$ & 5 & .. & 2 & 13 \\
\hline $101+$ & 1 & & 1 & & & 1 & 3 & 2 & 2 & 2 & 12 \\
\hline Unknown & 288 & 296 & 298 & 238 & 286 & 259 & 210 & 252 & 84 & 188 & $239 y$ \\
\hline
\end{tabular}

For the United States.

\begin{tabular}{c|r|r|r|r|r}
\hline $\begin{array}{c}\text { Age, } \\
\text { Limiting } \\
\text { Years. }\end{array}$ & $1875-76$ & $1876-77$ & $1877-78$ & $1878-79$ & Total. \\
\cline { 1 - 2 } $0-3$ & & & & & \\
\hline $3-7$ & 341 & 246 & 159 & 128 & 874 \\
$7-10$ & 357 & 276 & 368 & 305 & 1267 \\
$10-14$ & 275 & 243 & 278 & 287 & 1149 \\
$14-20$ & 243 & 173 & 194 & 307 & 1149 \\
$20-25$ & 160 & 113 & 164 & 161 & 875 \\
$25-30$ & 103 & 83 & 99 & 112 & 598 \\
$30-35$ & 17 & 20 & 32 & 44 & 113 \\
$35-40$ & 26 & 21 & 20 & 18 & 85 \\
$40-45$ & 8 & 12 & 8 & 14 & 42 \\
$45-50$ & 4 & 3 & 6 & 3 & 16 \\
$50+$ & 7 & 1 & 4 & 7 & 19 \\
Unknown & 164 & 107 & 153 & 94 & 518 \\
\hline
\end{tabular}

(e) The number of wrecks is to a large extent dependent on the character of the cargoes of the vessels wrecked. 


\section{Data :}

For Great Britain.

\begin{tabular}{|c|c|c|c|c|c|c|c|c|c|c|}
\hline - & 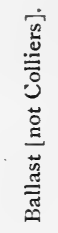 & نें & 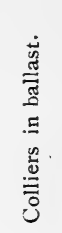 & 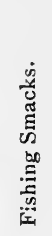 & 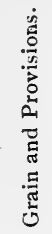 & 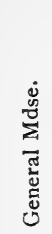 & 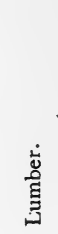 & 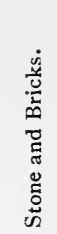 & 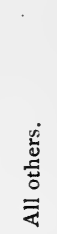 & さ્ّ \\
\hline $1864-65$ & 191 & 550 & 131 & 101 & 119 & 78 & 88 & 105 & 550 & 1913 \\
\hline $1865-66$ & 244 & 701 & 119 & 109 & 178 & 77 & 115 & 136 & 657 & 2336 \\
\hline $1866-67$ & 234 & 713 & 179 & 117 & 158 & 82 & 94 & 153 & 640 & 2370 \\
\hline $1867-68$ & 229 & 617 & 165 & 173 & 120 & 82 & 84 & 137 & 563 & 2170 \\
\hline $1868-69$ & 252 & 693 & 130 & 140 & 117 & 103 & 72 & 161 & 668 & 2306 \\
\hline $1869-70$ & 247 & $\tilde{5} 59$ & 160 & 124 & 145 & 114 & 116 & 164 & 597 & 2226 \\
\hline $1870-71$ & 202 & 541 & 96 & 91 & 139 & 77 & 89 & 125 & 644 & 2004 \\
\hline $1871-72$ & 218 & 524 & 104 & 126 & 105 & 88 & 52 & 101 & 572 & 1890 \\
\hline $1872-\pi 3$ & 278 & 788 & 100 & 100 & 244 & 116 & 168 & 166 & 732 & 2692 \\
\hline $1873-74$ & 256 & 539 & 67 & 165 & 131 & 110 & 161 & 175 & 587 & 2191 \\
\hline Means & 235 & 623 & 125 & 126 & 146 & 93 & 98 & 143 & 621 & 2210 \\
\hline
\end{tabular}

For the UNited States.

\begin{tabular}{|c|c|c|c|c|c|c|c|c|c|c|}
\hline $\begin{array}{l}1875-76 \\
1876-77 \\
1877-78 \\
1878-79\end{array}$ & $\begin{array}{l}474 \\
426 \\
413 \\
474\end{array}$ & $\begin{array}{l}273 \\
248 \\
244 \\
273\end{array}$ & .. & $\begin{array}{r}148 \\
74 \\
64 \\
38\end{array}$ & $\begin{array}{r}114 \\
61 \\
117 \\
103\end{array}$ & $\begin{array}{l}125 \\
129 \\
102 \\
125\end{array}$ & $\begin{array}{l}178 \\
224 \\
200 \\
466\end{array}$ & $\begin{array}{l}\mathbf{5 7} \\
28 \\
38 \\
23\end{array}$ & $\begin{array}{l}654 \\
697 \\
643 \\
521\end{array}$ & $\begin{array}{l}2023 \\
1887 \\
1821 \\
2023\end{array}$ \\
\hline Means... & 447 & 259 & & 81 & 99 & 120 & 267 & 36 & 629 & 193 \\
\hline
\end{tabular}

After making a liberal allowance for the large number of vessels engaged in certain kinds of trade, it still remains that there is an excessive number of wrecks corresponding to certain classes of cargoes. I do not pretend to offer any explanation of the questions raised by a study of these tables. I can only call attention to the need of a careful study of the hidden canses of the anomalies which they reveal.

In attempting to ascertain the ratio of wrecks which occur from preventable causes, I am limited to two sources of information; these are :

(a) The numerical data furnished by the Wreck Register for Great Britain, and by the reports of the Life Saving Service for the United states. 
(b) 'The comparison of the findings of the courts of inquiry upon the causes of wrecks, casualties and collisions, ordered by the British Board of Trade or reported to this Board. Both in Great Britain and in the United States an attempt is made to distinguish the causes of all the wrecks which occur. In the British Wreck Register these causes are grouped in four classes as follows:

\section{Class I.}

1. Foundering.

2. Driving or running on a sand or lee shore.

3. Parting cables.

4. Dragging anchors.

5. Damage to hull or rudder, or loss of masts, yards, sails, \&c.
6. Shifting of cargo or ballast.

7. Missing stays.

8. Failing to make harbor, or stranding whilst entering.

9. Capsizing.

\section{Class II.}

1. Error, neglect or incompetency of master or mate.

2. Error, neglect or incompetency of pilots.

\section{Class III.}

1. Unseaworthiness.

2. Overloading.

3. Defective charts, insufficient manning, unsound gear or equipments, imperfect repairs, or defective construction.
3. Improper stowage.

4. Not heaving lead.

\section{Class IV.}

1. Thick and foggy weather.

2. Heavy seas.

3. Strong currents and light winds.

4. Want of lights or buoys on coasts and shoals.

5. Want of pilot.

6. Want of power in steam tugs, or defective tow ropes.
4. Local attraction and defects of compasses.
\%. Striking on sunken wreck, \&c.

8. Spontaneous combustion.

9. Fire or lightning.

10. Damage to boilers or machinery.

11. Accident.

12. Combination of causes. 
In the reports of the Life Saving Service the causes are also grouped under four classes, but the arrangement is somewhat different from that given above.

In 187\%, the two causes, "damage to machinery," and " explosion of boiler, bursting of steam pipes, etc.," were separated from Class IV and were grouped in a class by themselves. In this investigation the original grouping has been retained.

These classes are:

\section{Class I.}

1. Foundered.

2. Stranded.

3. Sprung a leak.

4. Capsized.

5. Waterlogged.

6. Damage to hull, rigging, rudder, \&c.

7. Struck by lightning.

8. Machinery disabled.

9. Miscellaneous.

Class II.

1. Error in judgmẹnt.

4. Ignorance.

2. Error of pilot.

5. Carelessness.

3. Neglect of master.

\section{Class III.}

1. Defective instruments.

2. Defective hull, rigging, \&c.

\section{Class IV.}

1. Adverse currents.

2. Heavy sea.

3. Accidental.

4. Fire.

5. Never heard from.

6. Thick and foggy weather.

7. Misstayed.

8. Sprung a leak.

9. Becalmed.

10. Parted chains, \&c.

11. Struck bridges, piers, \&c.
12. Waterlogged.

13. Explosion.

14. Absence of proper lights.

15. Miscellaneous.

16. Ice.

1\%. Machinery disabled.

18. High wind.

19. Darkness.

20. Tides.

21. Unknown. 
Under the subdivisions given above we have the following data:

For Great Britain.

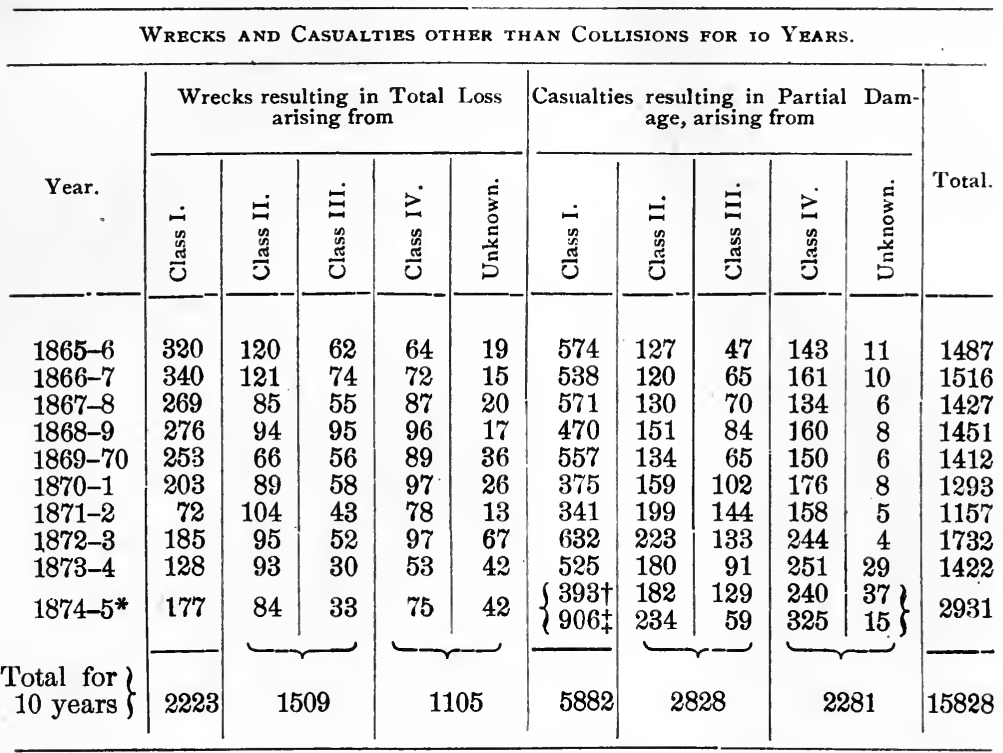

* In this year the partial damage is subdivided into + serious and $\ddagger$ minor casualties.

Fok the UNited States.

\begin{tabular}{c|c|c|c|c} 
Year. & Class I. & Class II. & Class III. & Class IV. \\
& & & & \\
\hline & & & & \\
$1865-6$ & 804 & 82 & 35 & 524 \\
$1866-7$ & 706 & 50 & 33 & 543 \\
$1867-8$ & 940 & 20 & 55 & 261 \\
$1868-9$ & 990 & 18 & 74 & 336 \\
\cline { 2 - 4 } Means & 860 & 42 & 49 & 416
\end{tabular}

From these figures it is impossible to draw other than very general conclusions. Since the causes enumerated in Class IV are about equally divided between those which may be classed as preventable and those which are non-preventable, we may with tolerable confidence compare Classes I and II.

It appears therefore that for the total number of wrecks excluding collisions, 45 , per cent are due to preventable canses. 
For the United States I can offer no explanation of the extremely small ratio of Class II to Class I. The omission of the cause "failure to heave the lead," suggests that the data is not altogether reliable. That this cause cannot be safely omitted will appear from the fact that between 1856 and 1872 , out of less than five hundred cases of punishmeńt imposed for default by English courts of inquiry, 102 were for "neglect of lead."

In 1865 the British Board of Trade began the yearly publication of a resume of the findings of the courts of inquiry instituted for ascertaining the causes of wrecks, and for the punishment of those convicted of default in navigation, by reprimand, by suspension or cancellation of certificates of competency, and even by fines and imprisonments. In the Wreck Register for 1873 there is a brief resumé of all the trials which occurred between 1856 and 1873. The total number is 1163. I have examined each of these findings, and selected those in which there is a clear acquittal from blame, care being taken to exclude all cases in which there is even an admonition, although the certificate was returned. From this examination it appears that there were 384 cases out of the total number 1163 in which the casualties occurred from causes clearly beyond the control of the master or mate.

From an examination of the findings between 1867 and $1874 \mathrm{I}$ find the following resul.ts :

$\begin{array}{cccccc}\text { Year. } & \begin{array}{c}\text { No. of } \\ \text { Acquittals. }\end{array} & \begin{array}{c}\text { Total No. } \\ \text { of trials. }\end{array} & \text { Year. } & \begin{array}{c}\text { No. of } \\ \text { Acquittals. }\end{array} & \begin{array}{c}\text { Total No. } \\ \text { of trials. }\end{array} \\ 1865 & 29 & 46 & 1870 & 86 & 251 \\ 1866 & 46 & 81 & 1871 & 44 & 130 \\ 1867 & 9 & 30 & 1872 & 70 & 169 \\ 1868 & 21 & 47 & 1873 & 38 & 102 \\ 1569 & 39 & 97 & 1874 & 122 & 314\end{array}$

We have here 504 clear acquittals in 1267 trials, giving a ratio not far different from that obtained from the findings between 1856 and 1872 , in which as nearly as can be made out the cases tried were different from those recorded in the annual volumes.

It is not to be understood that the findings in the remaining 763 trials are all for default of the master or mate, inasmuch as the inquiries often extend to their conduct after the casnalties occurred.

In the Register for 1876 there is a remarkable increase of the number of trials reported, covering the years 1874-5 and 1875-6. I copy the summary given : 


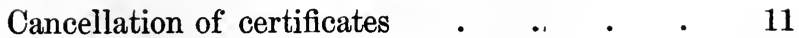

Suspension of certificates $\quad . \quad$. $\quad . \quad$. 204

Certificates returned $\quad . \quad$. $\quad . \quad . \quad$. 178

Unseaworthiness . $\quad . \quad$. $\quad . \quad . \quad . \quad 13$

Overloading, bad stowage $\quad . \quad$. $\quad . \quad$. 18

Defects in equipments . . . . .

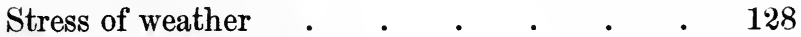

$\begin{array}{llllllll}\text { Fire or other accidents } & \text {. } & \text {. } & \text {. } & \text {. } & \text {. } & 68\end{array}$

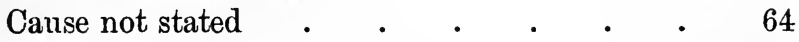

Total . . . 691

In both of these investigations there is one class of wrecks for which no cause can be safely assigned, viz. that involving vessels which were never heard from after sailing, for in these cases there are no records either of efforts made or of sufferings endured. The reports with respect to this class of wrecks are very defective. In the Wreck Register for 1874 there is for the first time a separate list of British ships not heard from after sailing. Of this class there were 83 in $1873-4,137$ in $1874-5$, and 101 in $1875-6$. The total number reported in the reports of the Life Saving Service for the years $1875-6$ to $1878-9$ is 59. It is probable that these numbers are somewhat too small, for according to the Insurance Reports of Great Britain there were between 1864 and 1869 (inclusive ?) 10,588 wrecks of which the end of 846 is unknown.

There is also another class of wrecks which may be much larger than is usually supposed, viz. wrecks for which it is exceedingly difficult to determine the true cause. In any given investigation it is imperative that the inquiry shall be extended beyond the immediate cause. A wreck may apparently occur by the act of God and yet be due to the previous folly of man. Take the case of the barque Providence, which sprung a leak in the Baltic on a voyage to Dantzic. After the crew had arrived at the last point of exhaustion in their efforts to stop the leak, it suddenly stopped, and the vessel arrived safely at her destination. .After the discharge of the cargo it was found that the leak had been caused by the giving way of a knot in a bottom plank, and that it had been stopped by a dead fish, which acted as a plug. If the vessel had been lost there would have been no evidence of the cause. As it turned out, the builder had to suffer the penalty for what might have been charged with apparent reason 
as an act of God. One can hardly tell where to place the case of the steamship L'Amerique of the French line between New York and Havre. She sprang a leak, and after being abandoned, was picked up and manned by a British crew, when it was found that through the ignorance of the engineer the donkey engine had been pumping water into instead of out of the ship.

Combining the results obtained from these independent inquiries, the general conclusion is reached that about one-half of all the wrecks which occur may be due to preventable causes.

Under the second head a complete and satisfactory investigation is wellnigh impossible. That the whole question of insurance in connection with wrecks involves more or less of fraud is evident from the following extract of a speech before the United Service Institution by Admiral Halstead, Secretary of Lloyds. He said: "The remedy for shipwrecks-what is it? I do not pretend for one instant to be able to provide a remedy, and I do not know anybody who can undertake to say what is a remedy; but I will tell you this: if I could go on the Stock exchange to-morrow morning, and by holding up my hand put a stop to all shipwrecks upon the coast, it would be a question how I could get safe with life off that Exchange. When I put that question to him (Lloyd) he said, 'It is perfectly true, you would stop our bread." "

As for definite data, it is only possible from the nature of the case to obtain a little here and a little there. The cases of the Dryad and the Harlequin, in $183 \%$, show that in those days at least the question of insurance had a very definite bearing upon the question of wrecks.

In 1866, Thomas Berwick was connected as an accessory in the destruction of ships owned by 'Thos. Berwick \& Son. On his trial he confessed to having destroyed no less than nine vessels in the conrse of twenty year's.

In 1867 there were in the Baltic 215 British vessels, and in 1868, 220 Swedish. The British vessels were largely insured, while on the Swedish vessels there was very little, if any insurance. Of these numbers, 17 British and 3 Swedish were lost. From 1857 to 1867 the ratio was 10 British to 3 Swedish. It is hardly probable that this disparity of numbers can be accounted for by the superior skill of the Swedish navigators.

'T'he data which I shall now offer will need to be taken with a large allowance for imperfect returns, but the near approach of the total insurance to the total value of the vessels and cargoes lost, and espe- 
cially the large excess of the insurance over the actual loss, proves either that the business of insurance involves enormous profits, or that it involves extensive fraud on the part of those who insure. As before, the returns are derived from the Wreck Register for $18 \% 5$, and from the annual reports of the Life Saving Service between 1875-6 and 1878-9.

For Great Britain.

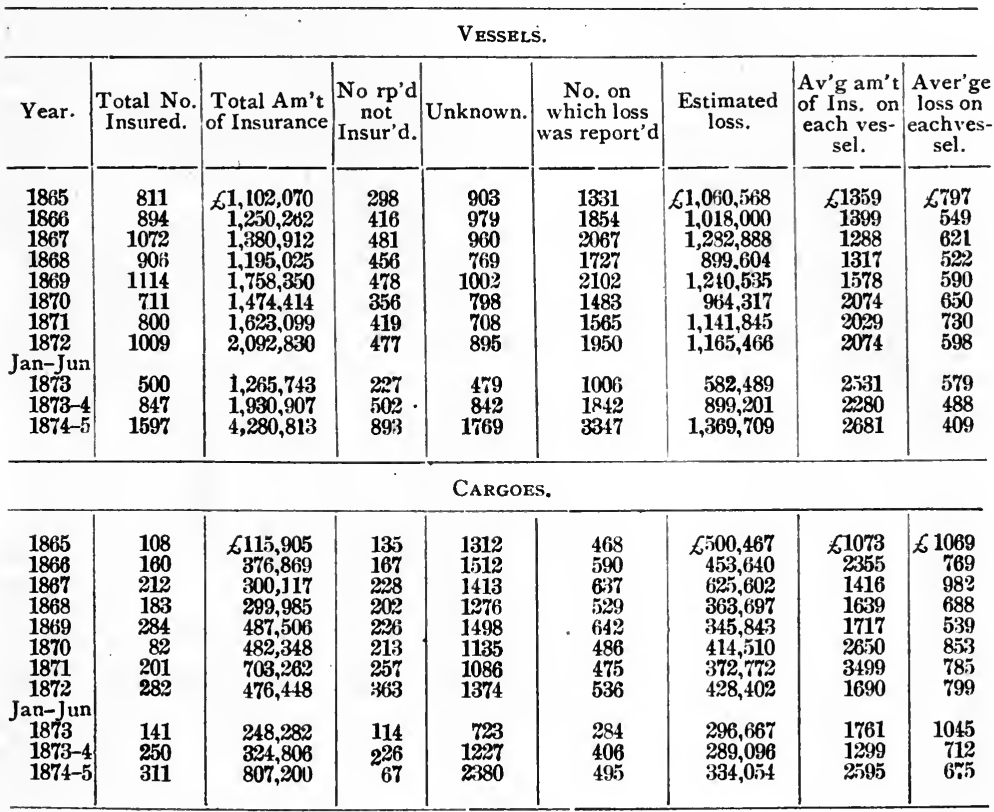

For the United States.

\begin{tabular}{|c|c|c|c|c|c|c|c|c|c|}
\hline & & & & VESS & LS. & & & & \\
\hline Year. & $\begin{array}{c}\text { Total } \\
\text { No. }\end{array}$ & $\begin{array}{c}\text { Total } \\
\text { Value. }\end{array}$ & $\begin{array}{l}\text { Total } \\
\text { No. }\end{array}$ & $\begin{array}{l}\text { Total } \\
\text { Loss. }\end{array}$ & $\begin{array}{c}\text { Total } \\
\text { No. }\end{array}$ & $\begin{array}{l}\text { Total Am't } \\
\text { Insured. }\end{array}$ & $\begin{array}{l}\text { Average } \\
\text { value of } \\
\text { each } \\
\text { vessel. }\end{array}$ & $\begin{array}{l}\text { Average } \\
\text { loss on } \\
\text { each } \\
\text { vessel. }\end{array}$ & $\begin{array}{c}\text { Average } \\
\text { Ins. on } \\
\text { each } \\
\text { vessel. }\end{array}$ \\
\hline $\begin{array}{l}1875-6 \\
1876-7 \\
1877-8 \\
1878-9\end{array}$ & $\begin{array}{l}1800 \\
1771 \\
1724 \\
1853\end{array}$ & $\begin{array}{r}\$ 33,839,675 \\
35,973,839 \\
29,195,845 \\
29,450,662\end{array}$ & $\begin{array}{l}1788 \\
1709 \\
1640 \\
1749\end{array}$ & $\begin{array}{r}\$ 7,025,192 \\
8,834,202 \\
6,963,084 \\
5,899,159\end{array}$ & $\begin{array}{l}807 \\
782 \\
748 \\
733\end{array}$ & $\begin{array}{r}\$ 11,677,106 \\
10,278,611 \\
8,681,180 \\
: 7,33 ;-011\end{array}$ & $\begin{array}{r}\$ 18,000 \\
20,313 \\
16,936 \\
15,893\end{array}$ & $\begin{array}{r}\$ 3929 \\
5169 \\
4246 \\
3373\end{array}$ & $\begin{array}{r}\$ 14,470 \\
13,118 \\
11,606 \\
10,012\end{array}$ \\
\hline
\end{tabular}

Cargoes.

\begin{tabular}{r|rr|rr|rr|r|r|r}
\hline $1875-6$ & 1307 & $\$ 17,333,636$ & 586 & $\$ 2,687,228$ & 487 & $\$ 8,589.516$ & $\$ 13,262$ & $\$ 1586$ & $\$ 17,638$ \\
$1876-7$ & 1283 & $21,230,636$ & 612 & $4,548,958$ & 598 & $11,882,253$ & 16,548 & 7433 & 19,870 \\
$1877-8$ & 1276 & $18,738,387$ & 621 & $\mathbf{3 , 9 7 9 , 8 0 6}$ & 562 & $\mathbf{9 , 6 7 8 , 1 1 0}$ & $\mathbf{1 4 , 6 8 5}$ & $\mathbf{6 4 0 9}$ & $\mathbf{1 7 , 2 2 1}$ \\
$1878-9$ & 1343 & $\mathbf{1 6 , 8 9 0 , 4 3 5}$ & $\mathbf{6 3 0}$ & $\mathbf{4 , 2 8 4 , 8 3 6}$ & $\mathbf{6 3}$ & $\mathbf{7 , 7 5 1 , 4 3 1}$ & $\mathbf{1 2 , 5 7 7}$ & $\mathbf{6 8 0 1}$ & $\mathbf{1 3 . 7 6 8}$ \\
\hline
\end{tabular}


Under the third heading my investigations are far from complete or satisfactory, on account of the difficulty of obtaining reliable data. The compass problem is an intricate one, and has never been fully solved, though the researches of Flinders, Barlow, Scoresby, Airy, and Harkness have done much to convert great uncertainty into tolerable certainty. The discovery of the deviation of the compass is undoubtedly due to Columbus, though the claim is sometimes put forward in behalf of one Peter Adsiger, based on a manuscript deposited in the University of Leyden. But Humboldt has shown that this claim is a spurious one. The first observations on the variation were by Bond, in 1668. But the variation is a very irregular one. There are both yearly, monthly, and diurnal inequalities, the diurnal variation being discovered by Graham in 1722. (The dip of the needle is said to have been discovered by Robert Norman in 15\%6.) 'The following short table of variations at Greenwich will illustrate both their magnitude and their irregularity.

$\begin{array}{lcccc}\text { Year. } & \begin{array}{c}\text { Mean variation } \\ \text { Greenwich. }\end{array} & \begin{array}{c}\text { Range } \\ \text { during year. }\end{array} \\ 1865 & 20^{\circ} & 32^{\prime} & 43^{\prime \prime} & 3^{\prime} \\ 1866 & 20 & 27 & 47 & 11 \\ 1867 & 20 & 20 & 17 & 7 \\ 1868 & 20 & 13 & 14 & 6 \\ 1869 & \ldots & \ldots & \ldots & 0\end{array}$

As an illustration of the monthly irregularity of variation, I give the Greenwich record for the first six months of 1841 :

\begin{tabular}{|c|c|c|}
\hline Month. & Variation. & $\begin{array}{l}\text { Change from one } \\
\text { month to next. }\end{array}$ \\
\hline Jan. & $23^{\circ} 11^{\prime} 46^{\prime \prime}$ & $+5^{\prime} 50^{\prime \prime}$ \\
\hline Feb. & $17 \quad 36$ & +142 \\
\hline Mar. & 1918 & -730 \\
\hline April & 1148 & +554 \\
\hline May & $17 \quad 42$ & -124 \\
\hline June & $16 \quad 18$ & \\
\hline
\end{tabular}

Here we have variations between different months amounting to nearly one-fourth of a degree. But the fluctuations of a single day are often more than for a whole month. These diurnal fluctuations are well illustrated by the following curve taken from the Greenwich observations of 1869 .

The variation for long periods is well illustrated by comparing Halley's Chart for 1700 with modern charts. But the complexity of the problem does not stop here.

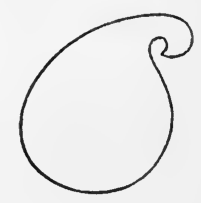


The tendency of the present tine is to build iron ships, and all ships now have more or less iron in their construction. 'These ships become to a greater or less degree themselves great magnets. In wholly iron ships the uncorrected deviation of the needle often amounts to $50^{\circ}$, thus rendering it wholly useless. - Captain Flinders in his voyage to Australia in 1811 was the first to make an intelligent discussion of this subject. 'The result of his investigations may be stated as follows:

I. A compass gives different bearings of the same object when placed in different parts of the ship.

II. When the ship's head is on the magnet meridian there is no effect from local attraction, showing that the various masses of iron on board act in unison with the earth's magnetism.

III. When the ship's head is east or west the effect of local attraction is the greatest, and that at intermediate points the deviation varies as the sine of the angular distance between the magnetic meridian and the bearing of the ship's head.

IV. The maximum variation is different in different parts of the world, varying as the distance from the magnetic equator.

The polar expeditions of 1818 fully confirmed Flinders' experiments. Before reaching Greenland the compass of the Alexandria differed from that of the Isabella $11^{\circ}$, and the same compasses gave results differing $11^{\circ}$ when placed in different parts of the ship. As the vessels passed up Davis straits all the compasses became sluggish. In Sir Edward Parry's passage through Barrow strait his compasses became totally useless. The admiralty law in regard to swinging for the variation of the compass is a very clear statement of the case. It reads as follows :

"As the deviation or error of the compass caused by local attraction of the ship becomes changed in amount by any change in the ship's geographical position, and may be entirely reversed in its direction by the ship's proceeding from the northern to the southern hemisphere, it is to be invariably tested by azimuth and amplitude observations at sea, and the ship is to be swung for ascertaining the change of error on arrival at a foreign station, and also once each year, and the same is to be inserted in the log-book and sent to the Admiralty with the quarterly return for December."

The next important discovery in this connection was by Barlow, who found that all the influence of iron bodies exerted on the compass resides on the surface. 'This discovery paved the way for Airy's 
method of correcting compasses, which is by swinging the ship in the usual way, and then correcting the local attraction of the ship by means of permanent magnets of soft iron conveniently placed with respect to the compass. But the most.important discovery was made by Dr. Scoresby. He found that every iron ship is itself a magnet, and that it gets its magnetism while building by the inductive magnetism of the earth, the poles of the ship's magnetism depending on the position of the building-yard and the direction of the keel in construction. Dr. Scoresby made the voyage of the world in the Royal Charter to test his theory, found by induction, and found it fully confirmed. Before starting his compasses were corrected by Airy's plan. On arriving at Melbourne it was found that a complete inversion of the ship's magnetic polarity had taken place. Every stanchion, every standard, every davit, every mass of iron about the deck had in its upper surfaces acquired a northern instead of a southern polarity, and the starboard compass had lost nearly onehalf of its original errors. On returning to the place of starting in the northern hemisphere, and swinging the ship, it was found that a re-inversion had taken place; but the compasses did not quite return to their original deviations, but retained a fraction of their errors. It has since been found that these changes are much greater in steam than in sailing vessels, as shown by observations on board the Vulcan (steam) and the Pandora (sailing).

In 1852-3 Dr. Scoresby, in a paper before the British Association, showed that there is a sensible difference in the deviation before and after steam is up. It is said that the compasses of a steam vessel when light and running before the wind with a high sea are practically useless.

Within a few years the effect of the heel of a ship on the deviation of the compass has been pretty fully investigated. In general it is found that when a ship's head is nearly $\mathrm{E}$ or $\mathrm{W}$ there is no sensible effect from heeling, that when it is $\mathrm{N}$ or $\mathrm{S}$ the effect is greatest, and that the marked end of the needle is attracted to the raised side of the ship in north latitudes, and vice versa in south latitudes. In iron ships $1^{\circ}$ of heel produces from $1^{\circ}$ to $2^{\circ}$ variation of the compass, generally about $1^{\circ}$. In a voyage of the City of Sydney, iron, 1100 tons, the deviation amounted to $22^{\circ}{ }^{\circ}$ for every degree of heel. This deviation may be almost wholly prevented by the use of elevated compasses.

Nore recent experience has shown that the magnetism of an iron ship does not attain its normal condition till some twelve months 
after launching, and that for some time after the variation is very irregular. In the Great Eastern, a fixed compass changed its deviation nearly three points in the first nine months of service. The observations of Professor Harkness on board a monitor seem to be conclusive on this point. It is apparent from this brief review that even with the utmost cantion, ships may be misled by unknown variations, and yet the London Compass Committee as late as 1869 declare that very few ships are lost from this cause. What shall be said of ships that are never swung and whose masters know nothing of the laws of variation? The loss of the City of Washington is the best refutation of this statement. One of the most intelligent captains I ever met, a man who has commanded vessels for thirty-six years, and who has been to almost every great port on the surface of the globe, told me he had never swung his ship and that he had never seen a ship swung.

The opinion of the London committee was probably founded on the small number of disasters arising from errors of the compass reported in the annual returns. Between 1865 and 1874-5 only 34 cases are set down as due to this cause, while in the findings of the courts of inquiry between 1856 and 1872 there are only 21 cases of this class. In the U. S. Reports there are recorded 20 cases between 1875-6 and 1878-9, but here the distinction is not always made between " error of compass" and "error of chronometer."

That other competent authorities hold to a view radically different from that expressed by the London committee will appear from the correspondence between the Royal Society and the Board of Trade, printed in the Shipping Returns for 1865 (vol. LXV, 1866). The correspondence opens with the following letter :

\section{Royal Socrety to the President of the Board of Trade.}

The Royal Society; Burlington House, 25 May, 1865.

Sir :-The attention of the Fellows of the Royal Society has been recently directed to the very great increase which has taken place in the employment of iron in the construction and equipment of ships, and the consequent augmentation of the embarrassments occasioned in their navigation by the action of the ship's magnetisn on their compasses.

The inconveniences which have already made themselves felt in the ships of the mercantile marine, and which threaten to be productive of very serious loss of life and property, unless remedial measures be adopted similar to those which have proved so advantageous to the ships of Her Majesty's navy, have induced the President and Council of the Royal Society, after much considera- 
tion, to venture on the step of calling your attention, as presiding over the Department of Trade, to a subject which they believe to be of pressing importance.

In this view, the accompanying memorandum has been prepared, stating as briefly as may be, the particulars which they are desirous of bringing under your consideration, in the beliel that the time has fully arrived when measures of a more stringent and effectual character are required in the direction which has been already taken by Her Majesty's government in such legislative enactments as those con'tained in the "Merchant Shipping Act, 1854," adverted to in the accompanying memorandum.

I have only to add, that it would afford the President and Council great satisfaction if they could be of any further assistance in a matter which they believe to be of so much importance.

(Signed)

I have, \&c.,

\section{Edward Sabine, \\ President of the Royal Society.}

In the memorandum referred to, attention is called-

1. To the great increase in the number of iron ships, as well as in the amount of iron used in the construction of such ships.

2. To the losses of iron ships.

3. To the advances which have been made in, and the present state of the science of the deviation of the compass.

Also, the attention of the Board of Trade is drawn to the proposition to secure under competent anthority-

(a) The correction of the compass in particular ships.

(b) The advancement of the science of the deviation of the compass.

(c) The education of masters and mates.

The reply of the Board of Trade to this communication contains a large amount of useful information, but fails, it seems to me, to grasp the vital point at issue, viz. the application to the mercantile marine of the system which has proved eminently satisfactory in the Royal navy.

The correspondence on the part of the Royal Society closes with the following communication:

'The Royal Society to Board of Trade.

Burlin gton House, 2d November, 1865.

Sir :-I have now laid before the Council of the Royal Society, your letter of the 25th of July, referring to the adjustment of the compasses of iron ships, and a copy of ny letter of the 28th of August, acknowledging its receipt and advert- 
ing to the inquiry you had made as to the preparation of a "manual" on the subject, together with your subsequent letter of $23 \mathrm{~d}$ October having reference to the same inquiry.

The President and Council are much disappointed by learning that the Board of Trade are not prepared to give effect to the recommendation that the system which has been found to work so successfully in the Royal navy, of combining official and competent superintendence with a proper code of instruction, should be extended to the mercantile marine. They consider such superintendence to be essential, not only to the general introduction of a good and efficient mode of compass correction into the mercantile marine, but eve $\mathrm{I}$ to the discharge of the duties having respect to the adjustment of the compasses of sea-going passenger steamers, with which the Board of Trade is already charged by the legislature.

In the memorandum accompanying my letter of the 25th of May it was stated that many recent losses of iron steamers have taken place, in which it is probable that compass errors have occasioned the loss. The President and Council think it right to call the attention of the Board of Trade to the serious responsibility they incur in cases of loss of life and property arising from the want of proper system of compass adjustment, by declining to take the course which is pointed out by the concurrent opinion of all competent advisers, as not only the best, but the only method of securing the introduction of such a system. They cannot but look forward to a time when the necessity of a proper supervision will be forced on the executive by public feeling, excited by some disastrous loss of human life traceable to the want of such superintendence.

The question is one of such vital importance that they desire to submit to the consideration of the Board of Trade the accompanying memorandum, replying in some detail to passages in your letter of 25 th July.

I have, \&c.,

(Signed)

$$
\begin{gathered}
\text { EDwakd Sabine, } \\
\text { President of the Royal Society. }
\end{gathered}
$$

As far as I can learn the compass problem still remains in the ' unsatisfactory state indicated by this correspondence.

[To be continued.] 



\section{THE PROCEEDINGS}

OF THE

\section{United States Naval Institute.}

Vol. VII. No. 4.

1882.

Whole No. 18.

NAVAL INSTITUTE, ANNAPOLIS, MD.

JANUARY 28, 1881.

Lieut.-Commander P. F. Harrington, U. S. N., in the Chair.

THE COEFFICIENT OF SAFETY IN NAVIGATION.

(Concluded.)*,

By Prof. W. A. Rogers, of Cambridge (U. S.) Observatory.

I now enter upon the consideration of the fourth topic. As has been already stated, the British government in 1714 offered a reward of $£ 20,000$ to any one who should discover the longitude at sea within thirty miles.

Two methods were proposed for the solution of the problem.

Morin proposed what is now substantially the lunar method; and Maskelyne devoted all his energies to the solution of the problem by observing astronomical phenomena, such as the eclipses of Jupiter's satellites. Maskelyne made a trial of this method during a voyage to Barbadoes, with an apparatus suspended from the rigging of a ship, called Irwin's marine chair. But the attempt was not successful, owing to errors occasioned by the motion of the ship.

On the other hand, mechanicians devoted every energy to the mechanical solution. Huygens had, as early as 1665 , in a voyage to the coast of Guinea, made the trial of the method by watches, without success. Trial of this method was now renewed with watches made

* See p. 205 et seq., No. 3, Vol. VII, Proceedings Naval Institute. 
by this maker, but it was soon found that the method would be of little value till some contrivance was devised for correcting errors produced by the variation of the temperature. At last Harrison, by the very perfection of his workmanship, produced a chronometer with which a trial of the coveted prize was made in a voyage to Jamaica. As the longitude of the island differed from that shown by his chronometer by only ten and three-quarter miles, he claimed the reward, which, after a successful second trial, was awarded to him.

We have, then, two essentially different methods for the determination of the longitude at sea:

(a) By lunar distances, occultations, and eclipses of Jupiter's satellites, \&c.

(b) By chronometers, assuming a constant rate throughout the entire voyage.

The latter method has for a long time been regarded as far more reliable than the former. Let us examine into the grounds of this opinion. We are, at the outset, met with the difficulty that in observations at sea we have no means of comparison with the truth. It is not sufficient to say that several observations agree with each other. Agreement inter se may be quite a different thing from agreement with the truth. We are obliged to have recourse to observations made on land, and then find, if possible, some means of comparing the value of these with those made at sea.

Even in the determination of the positions of fixed observatories, in which appliances for the utmost refinement are at hand, the values derived often vary widely from the truth. As late as 1755 , a century after the establishment of the observatory at Greenwich, the difference of longitude between that station and the Paris observatory was assumed to be $9 \mathrm{~m} .16 \mathrm{~s}$. Gen. Roy, in the progress of the trigonometrical survey of England, obtained the value $9 \mathrm{~m}$. $18.8 \mathrm{~s}$. In $17969 \mathrm{~m}$. 20s. was assumed to be the correct value. In 1830 it was found to be $9 \mathrm{~m} .21 .5 \mathrm{~s}$. from one thousand transits of moon and stars, while the actual difference, as determined by the telegraphic method, was found to be $9 \mathrm{~m}$. 20.6s. We have here a variation of 5.5s., or one and one-quarter miles.

The range of the earlier determinations of the difference between the longitude of Greenwich and Brussels is ten miles. A thorough discussion from moon culminations in 1836 gave a result which differs from that since found by the telegraphic method over $1 \mathrm{~s}$. To indicate the magnitude of the errors of longitude of the old State House, 
Boston, from transits of planets over the sun and from eclipses, I give the results of the several determinations by Dr. Bowditch:

\begin{tabular}{|c|c|c|c|}
\hline • & $\begin{array}{l}\text { State House from } \\
\text { Greenwich. }\end{array}$ & $\begin{array}{l}\text { Greenwich from } \\
\text { Harvard Col'ge. }\end{array}$ & $\begin{array}{l}\text { Deviation } \\
\text { f'm truth. }\end{array}$ \\
\hline om transit of Mercury. & h. m. s. & h. m. s. & $\begin{array}{c}s . \\
-0.7\end{array}$ \\
\hline Eclipse of the sun........1766 & 17.5 & 29.9 & +1.0 \\
\hline From transit of Venus . .....1769 & 18.0 & 30.4 & +0.5 \\
\hline Eclipse of the sun........1778 & 14.9 & 27.3 & +3.6 \\
\hline$\ldots .1791$ & 18.0 & 30.4 & +0.5 \\
\hline " .........1806 & 11.8 & 24.2 & +6.7 \\
\hline
\end{tabular}

We have here an absolute error of 2.2s., or more than one-half a mile, with a range of $10.3 \mathrm{~s}$. In passing, I may say that these results are a remarkable approximation to the true value, but they were deduced by one of the greatest and most practical mathematicians then living. They are, however, hardly comparable with any single observation, either on land or sea. During the time it would take an ordinary computer to "work up" these observations, a fast-sailing ship would be well on her journey around the world.

Perhaps the best illustration of the uncertainty resting upon the early determinations of longitude is furnished by the various values of the longitude of Washington, which have been given.

In 1822 Lambert found for the longitude of the Capitol :

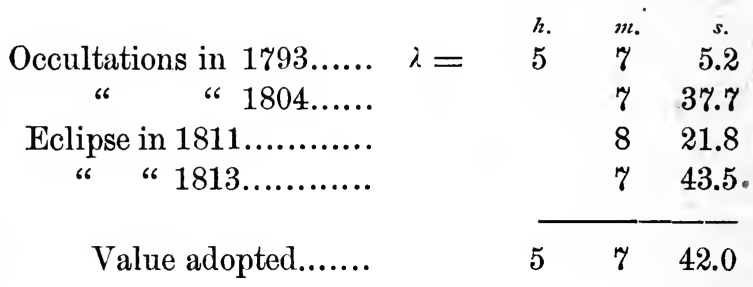

Elliott in the same year found $\lambda=5 \mathrm{~h} .8 \mathrm{~m}$. $7.2 \mathrm{~s}$. , but his value was rejected from the mean given above, on account of its supposed discordance. We have here a range of over nineteen miles, and the final value is nearly six miles in error.

Even in the determination of the longitude of the present observatory there is comparatively a wide range between the different results.

Adopting $\lambda=5 \mathrm{~h} .8 \mathrm{~m} .12 .1 \mathrm{~s}$., we have: 


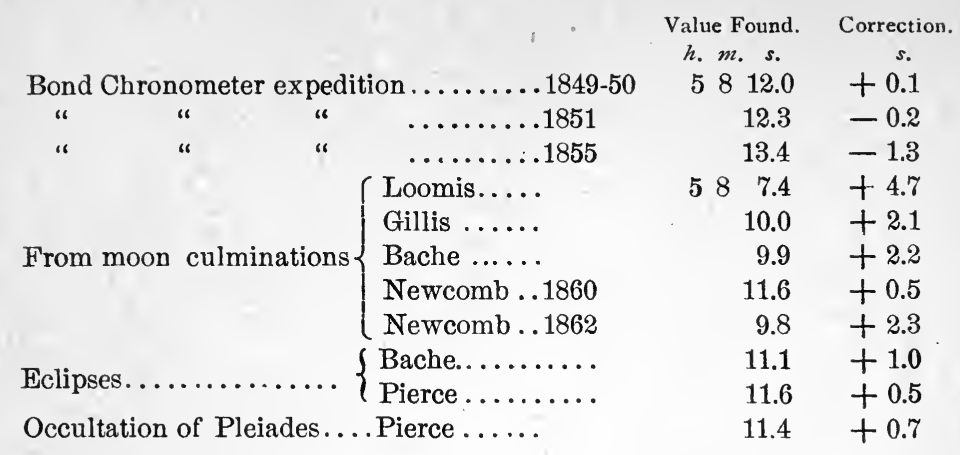

We have here a range of $6 \mathrm{~s}$, , or one and one-half miles, while the mean is in error $1.3 \mathrm{~s}$.

Two hundred and six moon culminations gave a longitude for San Francisco which has since been found to be 4 s. in error.

The telegraphic determination of the longitude of Lisbon, by Lt. Comdr. F. M. Green, U. S. N., giving a result 8s. different from the accepted value, is the most recent instance of an erroneous value.

These examples are sufficient to show that it is no easy task to determine accurately the geographical position of a point on the earth's surface, even under the most favorable conditions and with the most perfect instruments.

Resuming our investigation, we begin with moon culminations. These, though essentially the same in principle, are probably somewhat more accurate than lunars. With the exception of the Willet's Point observations of lunars, we are obliged to limit our investigation to observations of nearly the same class, viz. moon culminations. These are more accurate when the longitude depends upon observations at both of the stations to be determined, since the errors of the tables of the moon are thus for the most part eliminated.

In the case of a fixed observatory whose position has been ascertained by other and more accurate methods, we have the data for testing the accuracy of this method. Before the application of the telegraphic method of determining longitude, many observations of this class were made. I have collected and reduced the most important of these with the following results. All the observations made during a given year were grouped according to the limb of the moon observed. The number of observations for each limb and the number of years during which the observations were continued are given in the following table: 


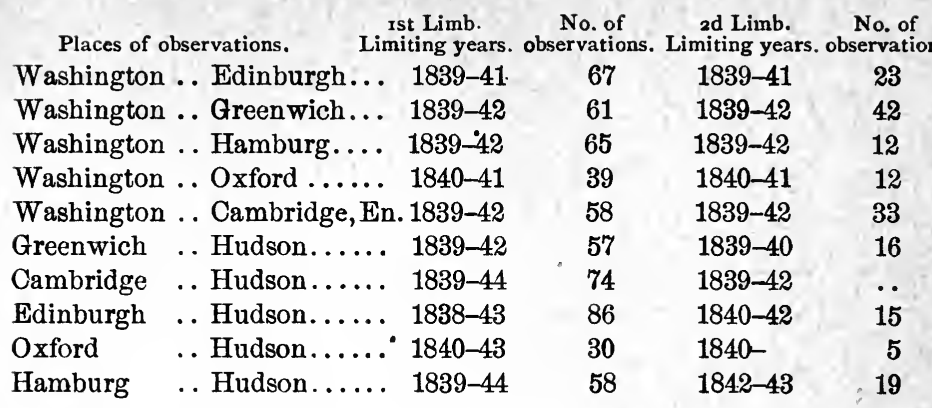

Omitting all details, the following results were obtained from these investigations:

Washington (Old Observatory) and Greenwich.

$$
\lambda=\begin{array}{ccc}
h . & m . & s . \\
5 & 8 & 2.2
\end{array}
$$

\begin{tabular}{|c|c|c|c|}
\hline $\begin{array}{c}\operatorname{Limb} \\
\text { of moon. }\end{array}$ & $\begin{array}{l}\text { No. of } \\
\text { obs. }\end{array}$ & $\begin{array}{l}\text { Mean } \\
\text { Corr. }\end{array}$ & $\begin{array}{l}\text { Extreme range } \\
\text { in each year. }\end{array}$ \\
\hline Woghington & bu & -1.3 & \\
\hline Washington .. Green wich....... & 41 & -1.0 & 23.0 \\
\hline Washington .. Greenwich via Edinburgh . II & $\begin{array}{l}64 \\
23\end{array}$ & $\begin{array}{l}-5.1 \\
-0.8\end{array}$ & 21.8 \\
\hline Washington .. Greenwich via Oxford.... II & $\begin{array}{l}32 \\
13\end{array}$ & $\begin{array}{l}-5.4 \\
-0.4\end{array}$ & 21.6 \\
\hline Washington .. Greenwich via Cambridge II & $\begin{array}{l}57 \\
23\end{array}$ & $\begin{array}{l}+0.8 \\
-4.6\end{array}$ & 19.9 \\
\hline Washington .. Greenwich via Hamburg. . II & $\begin{array}{l}69 \\
12\end{array}$ & $\begin{array}{l}-2.6 \\
-2.5\end{array}$ & 21.6 \\
\hline
\end{tabular}

Washington and Edinburgh.

Observations at each Station.

No. observations. $\begin{gathered}\text { Average deviation } \\ \text { from mean for } \\ \text { each year. }\end{gathered} \quad \begin{gathered}\text { Extreme range } \\ \text { between different } \\ \text { years. }\end{gathered}$

$\begin{array}{lll}2.4 \mathrm{~s} . & 21.8 \mathrm{~s} & 3.6\end{array}$

Oamp Riley, Boundary between United States and Mexico.

From tabular places of the moon. Conparison with mean value. 


\section{Hudson, Ohio.}

Comparison with the mean value of series.

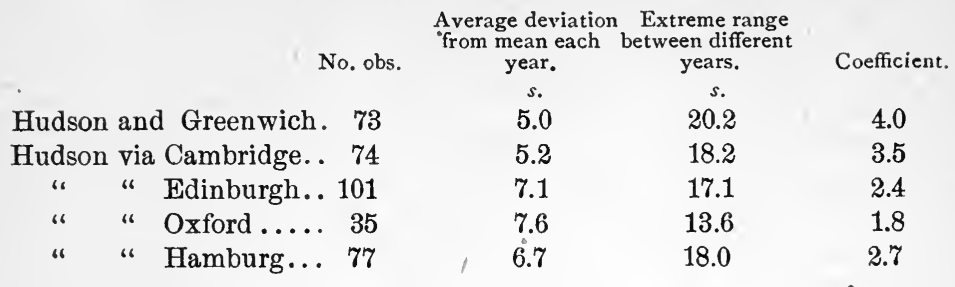

\section{Brussels and Greenwich.}

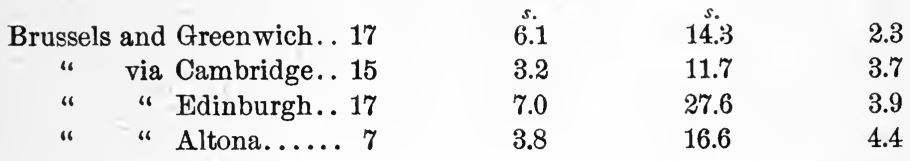

F. G. W. Struve in Turkey with 22-inch Transit. Comparison with mean value.

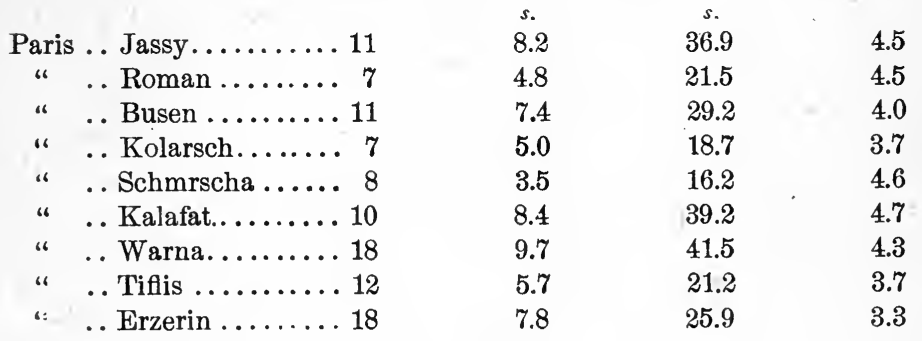

\section{Willet's Point.}

Comparison with transit observations.

From moon culminations.

$\begin{array}{rrrrrr} & & & s . & s . & \\ \text { American. . } 1869 & 18 & 12.6 & 64.4 & 5.1 \\ \text { Ephemeris. } 1871 & 17 & 14.5 & 67.5 & 4.7 \\ 1872 & 12 & 7.2 & 31.3 & 4.4 \\ & 6 & 2.9 & 9.0 & 3.1 \\ \text { British .... } 1869 & 18 & 12.5 & 47.9 & 3.8 \\ \text { Ephemeris. } 1871 & 18 & 16.6 & 71.0 & 4.3 \\ & 1872 & 6 & 17.7 & 76.9 & 4.3 \\ & 18 & 8.9 & 24.4 & 2.7\end{array}$


THE COEFFICIENT OF SAFETY IN NAVIGATION.

From lunar distances.

1870

$\begin{array}{rrrr} & s . & s . & \\ . . & 34.9 & 67.4 & 1.9 \\ . . & 37.8 & 143.0 & 3.8 \\ . . & 49.5 & 80.9 & 1.6\end{array}$

As an illustration of the error of Mr. Main's statement that the lunar problem is completely solved, I add the details from the Willet's Point observations for 1871 :

From Moon Culminations.

\begin{tabular}{|c|c|c|c|}
\hline \multicolumn{2}{|l|}{ Date. } & $\begin{array}{l}\text { Corr. by British } \\
\text { Ephemeris. }\end{array}$ & $\begin{array}{l}\text { Corr. by American } \\
\text { Ephemeris. }\end{array}$ \\
\hline January & 30 & - 5.2 & -17.1 \\
\hline September & 25 & -24.2 & -9.1 \\
\hline “" & 26 & +14.9 & +1.6 \\
\hline “ & 27 & +11.0 & +1.4 \\
\hline “ & 27 & +2.2 & -8.4 \\
\hline “ & 28 & -2.9 & $\cdots$ \\
\hline “ & 28 & -16.2 & -12.1 \\
\hline “ & 29 & -10.1 & -10.0 \\
\hline October & 23 & -14.6 & +11.9 \\
\hline “ & 27 & +7.8 & +0.9 \\
\hline “ & 27 & +18.9 & +14.2 \\
\hline “ & 28 & +50.2 & +0.0 \\
\hline “ & 28 & +52.7 & +0.1 \\
\hline
\end{tabular}

From Lunar distances for $18 \% 0$. With Sextant.

\begin{tabular}{crc}
\multicolumn{2}{c}{ Date. } & Corr. \\
January & 27 & \\
September & 3 & +19.1 \\
October & 19 & +47.0 \\
“ & 29 & -18.4 \\
“ & 30 & -1.0 \\
November & 1 & -0.2 \\
“ & 6 & -38.0 \\
“ & 29 & -96.0 \\
\end{tabular}

Finally, we have fortunately on this point positive and conclusive testimony from the observations of Mr. Fisher, astronomer on Capt. Parry's second voyage. He found that the mean of 2500 observations in December differed ten miles from the mean of 2500 in the following March, and that the mean of a still larger number made on both ships differed ten miles from those in March and twenty-four miles from those in December. It is the testimony of Capt. Heywood that any set of lunars may be expected to differ $6^{\prime}$ or $7^{\prime \prime}$ from any other 
set equally good, taken at a different time of the year, and this independently of accidental errors.

Collecting results, we have :

Place and Circumstances of Observation.

Greenwich-Edinburgh. Observations at each station, compared final result with truth ..........

Washington-Greenwich. Observations at each station, compared final result with truth .........

Hudson-Greenwich, compared with mean result for each station.........................

Brussels-Greenwich, compared with mean result for each station ......................

Places in Turkey with Paris, compared with mean

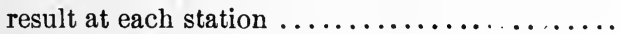

Camp Riley, comp'd of mean with tabular places. .

Willet's Point, compared with transit observations-

From American Ephemeris...............

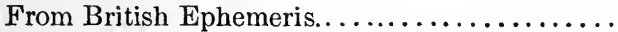

Lunars compared with known positions.........

$\begin{array}{ccc}\begin{array}{c}\text { Average } \\ \text { error. }\end{array} & \begin{array}{c}\text { Range bet. } \\ \text { greatest } \\ \text { and least. } \\ s .\end{array} & \begin{array}{c}\text { Coeff- } \\ \text { cient. }\end{array} \\ 2.4 & 21.8 & 9.0 \\ & . & \\ 2.1 & 21.6 & 10.3 \\ & & \\ 6.3 & 17.4 & 2.9 \\ & & \\ 5.0 & 17.6 & 3.5 \\ & & \\ 6.7 & 27.8 & 4.1 \\ 14.0 & 55.0 & 3.9 \\ & & \\ 9.3 & 43.0 & 4.6 \\ 14.0 & 55.0 & 3.9 \\ 40.7 & 97.1 & 2.4\end{array}$

For fixed observatories, with the most perfect instruments, we must therefore expect from the lunar method of moon culminations an absolute error of 2.2s. within a range of 21.6s. as the result of any number of observations. These results correspond in a general way with an investigation made by Professor Pierce. He found the ultimate limit to be $\pm 0.55 \mathrm{~s}$. when one limb of the moon was observed. He says: "Beyond this it is impossible to go with the utmost refinement. By heaping error upon error, it may crush the influence of each separate determination, but does not diminish the relative height of the whole mass of discrepancy. But this discrepancy between the results for different limbs of the moon often amounts to 10s. in the mean determination of a year." The assumption that the ultimate limit of accuracy is as great as 1 s. seems to be a very moderate widening of the limits. I find it to be 2.2s.

For fixed observatories, comparing with the mean result at any station, we must expect a relative error of $6.0 \mathrm{~s}$., with a range of $20.9 \mathrm{~s}$.

For fixed observatories, using the moon's tabular places, we must expect an error of $12.4 \mathrm{~s}$. with a range of $51.0 \mathrm{~s}$.

For lunar distances, with the sextant, on land, we must expect an error of 40.7 s., with a range of $9 \% .1 \mathrm{~s}$.

For single lunar observations at sea these quantities should have a coefficient at least as great as three additional units. 
It will be noticed that the coefficient is much larger for comparisons with known values than for comparisons with the mean of a given series.

I now take up the subject of chronometers, and make a similar investigation.

The sources of error are:

(a) Variations of rate, arising from the action of magnetism.

The only observations under this head that I can find are those made by Mr. Fisher and by Professor Airy. Mr. Fisher made a very elaborate series of experiments, from which he found that the earth's magnetism changed the daily rate in one case $4.5 \mathrm{~s}$., in another $3.2 \mathrm{~s}$., and in another 4.1s.

Professor Airy made similar experiments and found similar results, the extreme variation on account of the influence of terrestrial magnetism being 5.8s. He found the following rates for Brockbanks, No. 425:

When the figure-

$$
\begin{aligned}
& \text { XII was north, rate }=4.64 \mathrm{~s} \text {. } \\
& \text { " " east " }=8.70 \\
& \text { " " south " }=9.61 \\
& \text { " " west " }=5.75
\end{aligned}
$$

He also found that the action of terrestrial magnetism could be eliminated by placing the chronometer on the top of a compass-box whose needle was perfectly free, provided the elevation was properly adjusted. When this adjustment was made he found for-

$$
\begin{aligned}
\text { XII N. rate } & =9.24 \mathrm{~s} . \\
\text { " E. } " & =9.41 \\
\text { " S. } ~ & =9.75 \\
\text { " W. } ~ & =10.03
\end{aligned}
$$

'This corresponds with my own observations in the case of clocks. I have long noticed that the Cambridge and Boston clocks gain and lose together, due to some kind kind of a sympathetic action between the two.

(b) When chronometers are swung on the same support it is probable there is a sympathetic action between them similar to the results recently found with the transit of Venus clocks.

(c) Variation on account of change of barometric pressure. This varies between $.3 \mathrm{~s}$. and .8s. per day for every inch of change in the barometer. 
(d) Variation between land and sea rates. The elder Professor Bond made a full investigation of the average difference between the land and sea rate, and found them essentially the same. It had been previously assumed that there was an average gain of the latter over the former. But in individual cases there are, without doubt, great changes of the rate, arising mostly from careless handling in transportation to the ship.

Almost every chronometer will change its rate when its circumstances, either of rest or motion, are changed. The Boston standard clock of Messrs. Bond \& Son almost invariably has a different rate on Sunday from any other day of the week. So, also, it takes a new rate when the streets are covered to any considerable depth with snow.

The jar of machinery affects the rate; hence the rate of a sailing vessel is more steady than that of a steamer.

(e) Variation of rate at sea, on account of change of temperature.

Mr. Hartnup, of Liverpool, was the first to give the chronometer rate for different temperatures. So far as I can find he is the only one who does so now, and yet failure in this respect occasions errors of enormous magnitude. In one case which Mr. Hartnup instances, if the navigator had relied upon his average rate he would have been nearly sixty miles in error. This is a reform in rating chronometers which is imperatively demanded, and it is one easily accomplished.

Let us now attempt to determine the limits within which a chronometer can be depended on to give the longitude at sea. Here we are limited in a great measure to the performances of chronometers on land, inasmuch as at sea we have no means of comparison with a normal standard. The chronometer tests at the Greenwich observatory, however, afford abundant facilities for ascertaining the performance of chronometers under varying conditions of temperature. I select for discussion three series-the first from 1842 to 1852, the second from 1853 to 1862 , and the third from $18{ }^{\circ} 3$ to $18 \% 1$. The quantities to be determined are the greatest difference between the rates during a given trial, which usually extended over a period of about six months, and the greatest difference of rates between one week and the next following.

The only rule followed in the selection of the chronometers chosen for these tests has been the preference given to makers who entered their chronometers the greatest number of times during the entire interval from 1842 to 1871 . The method of proceeding was as follows : Har- 
ing selected for this test, e.g., the chronometers of Frodsham, the quantities songht were obtained from the chronometer tests recorded in the volumes of the Greenwich observations between the years 1842 and 18\%1. Inasmuch as the value given for each group is a mean value, derived from the. number of chronometers entered for trial between the limiting dates, I have added the greatest value for a given series. The addition of these columns is important, since the liability to error is as great as the greatest range of error.

The temperature at which the comparisons were made varies from about $35^{\circ}$ to about $95^{\circ}$ Fahrenheit. The variation of rate under nearly the same temperature will appear from the column "Greatest range in daily rate between one week and the next following."

Chronometer rates determined at the Greenwich ObserVATORY UNDER VARYING CONDITIONS OF TEMPERATURE.

\begin{tabular}{|c|c|c|c|c|c|c|c|c|c|c|c|c|c|c|c|}
\hline Mak & . & 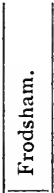 & 芯 & 苟 & 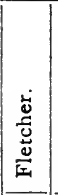 & 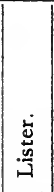 & 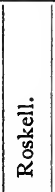 & 芯 & 莺 & $\stackrel{\ddot{\circ}}{\circ}$ & 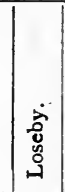 & 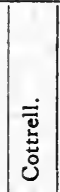 & 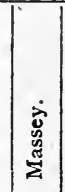 & 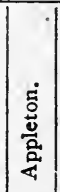 & 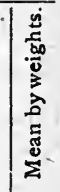 \\
\hline $\begin{array}{l}\text { ber of Chro- } \\
\text { neters. }\end{array}$ & & $\begin{array}{l}9 \\
6 \\
9\end{array}$ & $\begin{array}{r}10 \\
10 \\
9 \\
\end{array}$ & $\begin{array}{l}7 \\
9 \\
8\end{array}$ & $\begin{array}{l}7 \\
2 \\
7\end{array}$ & $\begin{array}{r}6 \\
10 \\
8\end{array}$ & $\begin{array}{l}4 \\
\mathbf{5} \\
\mathbf{5}\end{array}$ & $\begin{array}{l}7 \\
9 \\
4\end{array}$ & $\begin{array}{r}\cdots \\
3 \\
7\end{array}$ & $\begin{array}{r}9 \\
10 \\
5\end{array}$ & \begin{tabular}{c|c|}
9 & \\
0 & \\
5 & 1 \\
5 &
\end{tabular} & $\begin{array}{c}7 \\
\cdots\end{array}$ & $7 \mid \begin{array}{c}9 \\
. . \\
\cdots\end{array}$ & .. & $\ddot{*}$ \\
\hline $\begin{array}{l}\text { Treatest range of } \\
\text { daily rate dur- } \\
\text { ing trial. }\end{array}$ & $\left\{\begin{array}{l}184 \\
185 \\
186\end{array}\right.$ & $\begin{array}{c}s . \\
3.37 \\
2.67 \\
2.41\end{array}$ & $\begin{array}{c}s . \\
2.74 \\
3.91 \\
1.79\end{array}$ & $\begin{array}{c}s . \\
3.20 \\
3.25 \\
2.24\end{array}$ & $\begin{array}{c}s . \\
3.74 \\
3.47 \\
3.72\end{array}$ & $\begin{array}{c}s . \\
4.40 \\
3.64 \\
2.06\end{array}$ & \begin{tabular}{|l|}
$s$. \\
5.56 \\
6.11 \\
2.71
\end{tabular} & $\mid$\begin{tabular}{c|}
$s$. \\
2.43 \\
5.00 \\
3.54
\end{tabular} & $\mid \begin{array}{c}s . \\
3 . \dot{7} 2 \\
1.85\end{array}$ & $\mid \begin{array}{c}s . \\
3.21 \\
3.14 \\
2.20\end{array}$ & \begin{tabular}{|c|c|} 
& $s$. \\
1 & 2.07 \\
4 & 3.24 \\
0 & $\cdots$
\end{tabular} & $\begin{array}{c}s . \\
3.70 \\
\because . \\
\cdots\end{array}$ & $\left|\begin{array}{c}s . \\
3.39 \\
\ldots \\
\cdots\end{array}\right|$ & $\mid \begin{array}{c}s .90 \\
\cdots \\
\cdots\end{array}$ & $\begin{array}{l}s . \\
3.4 \\
3.8 \\
2.4\end{array}$ \\
\hline $\begin{array}{l}\text { Greatest range in } \\
\text { given series. }\end{array}$ & $\left\{\begin{array}{l}18 \\
18 \\
186\end{array}\right.$ & $\begin{array}{l}5.56 \\
4.16 \\
4.40\end{array}$ & $\begin{array}{l}7.74 \\
5.31 \\
2.91\end{array}$ & $\mid \begin{array}{l}5.90 \\
4.70 \\
2.87\end{array}$ & $\begin{array}{l}5.59 \\
4.14 \\
3.49\end{array}$ & $\begin{array}{l}8.73 \\
7.00 \\
2.41\end{array}$ & $\begin{array}{l}9.11 \\
1260 \\
4.24\end{array}$ & $\begin{array}{l}3.39 \\
7.50 \\
5.60\end{array}$ & $\begin{array}{l}5.60 \\
2.63\end{array}$ & $\mid \begin{array}{l}5.50 \\
6.77 \\
2.77\end{array}$ & \begin{tabular}{c|c}
0.59 \\
7.24 \\
$\cdots$
\end{tabular} & 6.40 & $0 \begin{array}{c}7.57 \\
\cdots \\
\cdots\end{array}$ & $\begin{array}{c}3.97 \\
\because \\
\because\end{array}$ & $\begin{array}{l}\mathbf{5 . 7 5} \\
\mathbf{6 . 1 0} \\
3.48\end{array}$ \\
\hline $\begin{array}{l}\text { Greatest range of } \\
\text { daily rate bet. } \\
1 \text { week and the } \\
\text { next following. }\end{array}$ & $\left\{\begin{array}{l}1842 \\
185 \\
1863\end{array}\right.$ & $\begin{array}{l}1.87 \\
1.79 \\
1.20\end{array}$ & $\begin{array}{l}1.54 \\
1.93 \\
1.01\end{array}$ & $\begin{array}{l}2.06 \\
1.73 \\
1.07\end{array}$ & $\begin{array}{l}1.56 \\
1.34 \\
0.87\end{array}$ & $\begin{array}{l}2.50 \\
1.79 \\
1.16\end{array}$ & $\left|\begin{array}{l}3.24 \\
2.70 \\
1.81\end{array}\right|$ & $\begin{array}{l}1.67 \\
2.29 \\
2.47\end{array}$ & $\left|\begin{array}{l}\ddot{1} 33 \\
0.83\end{array}\right|$ & $\begin{array}{l}1.93 \\
1.63 \\
1.13\end{array}$ & \begin{tabular}{|c|c|}
3 & 0.99 \\
3 & 2.17 \\
3 & $\cdots$ \\
\end{tabular} & $\left|\begin{array}{c}2.14 \\
\ddot{.}\end{array}\right|$ & $\mid \begin{array}{c}1.76 \\
\ddot{.}\end{array}$ & $\begin{array}{c}1.76 \\
\because \\
\cdots\end{array}$ & $\left\{\begin{array}{l}1.91 \\
1.88 \\
1.19\end{array}\right.$ \\
\hline $\begin{array}{l}\text { yreatest range in } \\
\text { given series. }\end{array}$ & & $\begin{array}{l}3.04 \\
2.79 \\
2.3\end{array}$ & $\begin{array}{l}2.87 \\
3.30 \\
1.90\end{array}$ & $\left|\begin{array}{l}4.91 \\
3.64 \\
1.60\end{array}\right|$ & $\left|\begin{array}{l}3.01 \\
1.43 \\
1.53\end{array}\right|$ & $\begin{array}{l}3.63 \\
3.71 \\
1.97\end{array}$ & $\begin{array}{l}6.37 \\
6.49 \\
4.11\end{array}$ & $\begin{array}{l}3.10 \\
5.57 \\
4.87\end{array}$ & $\mid \begin{array}{c}1.53 \\
1.36\end{array}$ & $\begin{array}{l}3.53 \\
4.60 \\
1.44\end{array}$ & $\begin{array}{c}1.66 \\
2.17 \\
\cdots\end{array}$ & $\begin{array}{c}4.51 \\
\because \\
\because\end{array}$ & $\mid \begin{array}{c}5.00 \\
\because \\
\cdots\end{array}$ & $\mid \begin{array}{c}3.00 \\
\cdots \\
. .\end{array}$ & $\begin{array}{l}3.74 \\
3.52 \\
2.35\end{array}$ \\
\hline
\end{tabular}

In order to exhibit still further the variations due to a change of temperature I have selected from the Greenwich reports for the years 1867-68-69-70-71 five chronometers showing the best performance, and five showing the poorest performance. The observations cover a period of four weeks, during which time the chronometers were subjected to a high temperature (abont $95^{\circ}$ ), and during the period of four weeks immediately preceding, under ordinary temperature. 
The headings explain the operations performed.

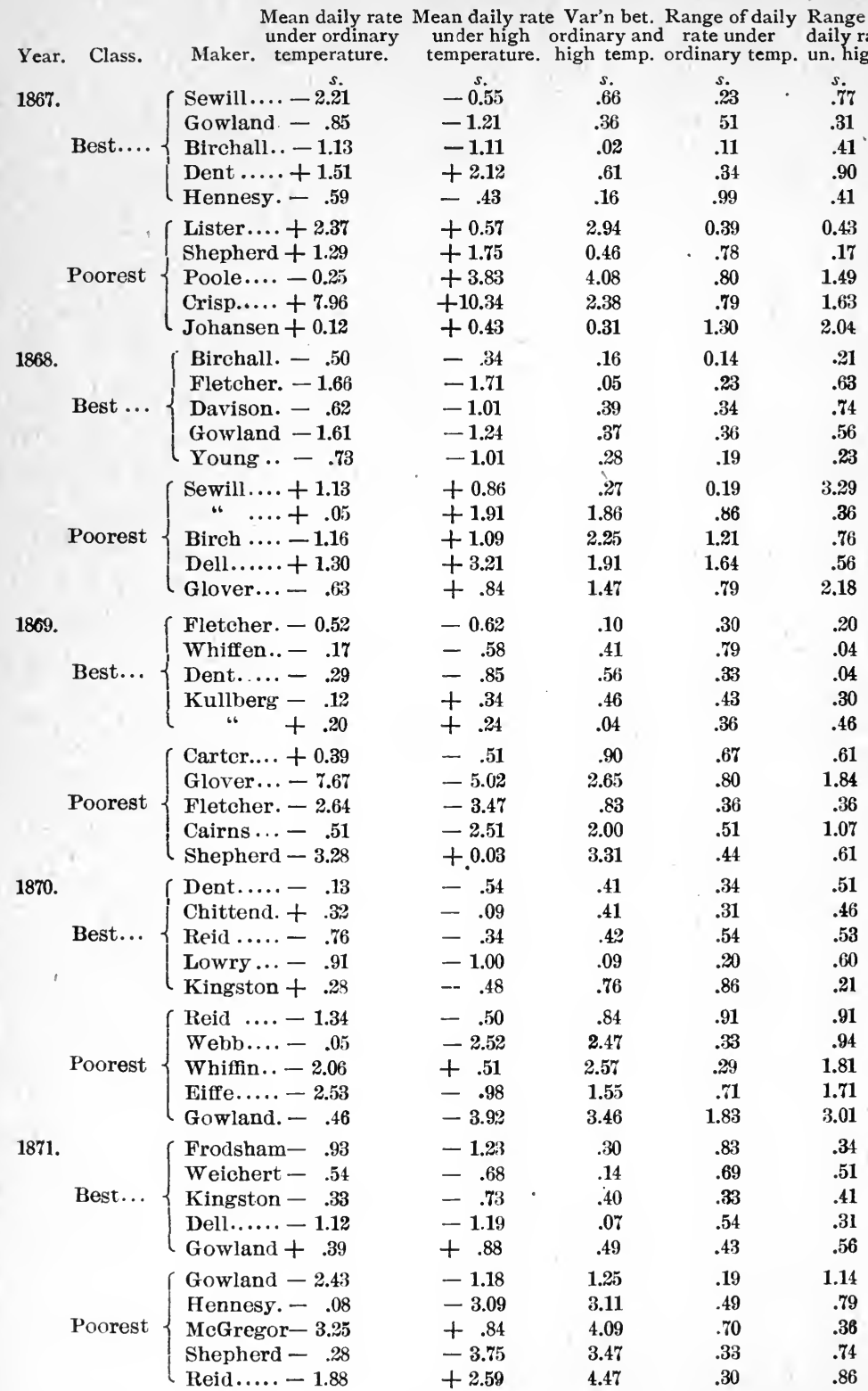




\title{
Summary.
}

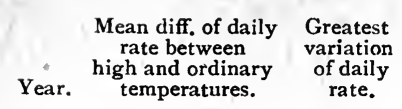

$\begin{array}{lll} & s . & s . \\ 1867 & .36 & .66 \\ 1868 & .25 & .39 \\ 1869 & .32 & .56 \\ 1870 & .39 & .76 \\ 1871 & .28 & .49 \\ & - & - \\ \text { Means } & .32 & .57\end{array}$

\begin{abstract}
Range of daily Range be- Range of Range berate under or- tween dif- daily rate un- tween difdinary temper- ferent chro- der high tem- ferent chroature in $\mathrm{I}$ mo. nometers. perature in $\mathrm{r}$ mo. nometers.
\end{abstract}

Best.

$\begin{array}{lccc}s . & s . & s . & s . \\ .44 & .88 & .56 & .51 \\ .25 & .22 & .47 & .53 \\ .44 & .49 & .21 & .42 \\ .45 & .55 & .46 & .39 \\ .56 & .50 & .43 & .25 \\ - & - & -43 & - \\ .43 & .53 & .43 & .42\end{array}$

Poorest.

\begin{tabular}{rrrrrrr}
1867 & 2.03 & 4.08 & .80 & .91 & 1.15 & 1.87 \\
1868 & 1.55 & 2.25 & .94 & 1.45 & 1.43 & 2.93 \\
1869 & 1.94 & 3.39 & .55 & .54 & .90 & 1.48 \\
1870 & 2.18 & 3.46 & .81 & 1.54 & 1.70 & 2.01 \\
1871 & 3.28 & 4.47 & .40 & .51 & .78 & .78 \\
\hline Means & $\mathbf{2 . 2 0}$ & $\underline{.53}$ & $\underline{.70}$ & $\underline{0.97}$ & $\underline{1.19}$ & $\frac{1.81}{1.51}$
\end{tabular}

From these tables I draw the following conclusions :

(a) There was a very marked and steady improvement in the construction of chronometers between 1842 and 18\%1. The greatest range of daily rate during the entire trial fell from 3.40 s. in 1842-52 to 2.41s. in 1863-71. 'The greatest range of the daily rate between one week and the next following was reduced from 1.91s. in 1842-52 to $1.19 \mathrm{~s}$. in 1863-71. These were the palmy days of ehronometer construction. I have made only a partial discussion of the trials since $18 \% 1$, but the evidence is pretty conclusive that the averages are larger than for the period 1863- 71 .

(b) Under the most favorable conditions for the excellent performance of chronometers, the average change of the rate between one week and the next following exceeds 1.2s. Of course, with the newly acquired rate the accumulation of error will be proportional to the time until another change takes place.

(c) The average liability to error in the daily rate between one week and the next following is not far from 3 seconds.

(d) 'The ratio-value between the average of first-class chronometers and the average of poor ones is nearly as 1 to $\%$ 
On the Magnitude of the Errors of Chronometers employed in Short and Regular Sea Voyages.

It will be allowed on every hand that a discussion of the actual errors of the chronometers used on the Cunard line of steamships will exhibit results considerably better than the general average. The well-known skill of the navigators in the service of this company, the perfection of every appliance, the general sameness of the conditions of each voyage, the number of chronometers employed, and the accurate rating of each chronometer at the beginning and end of each voyage by comparison with the time from fixed observatories, all conspire to give the most favorable results which can be expected from the performance of chronometers in the present state of chronometer construction. With the assistance of Mr. Aug. McConnell, I'have made a discussion of the chronometer errors of the Cunard steamers sailing between Liverpool and Boston during the years 1871-1872 and 1873.

\section{Chronometer Rates on Cunard Steamers.}

Steamer. Date of Length $\begin{array}{ccc}\text { arrival } & \text { Total error at end of Voyage. } \\ \text { at Boston, voyage. Chron. No. I. Chron. No.2. Chron }\end{array}$

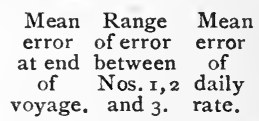

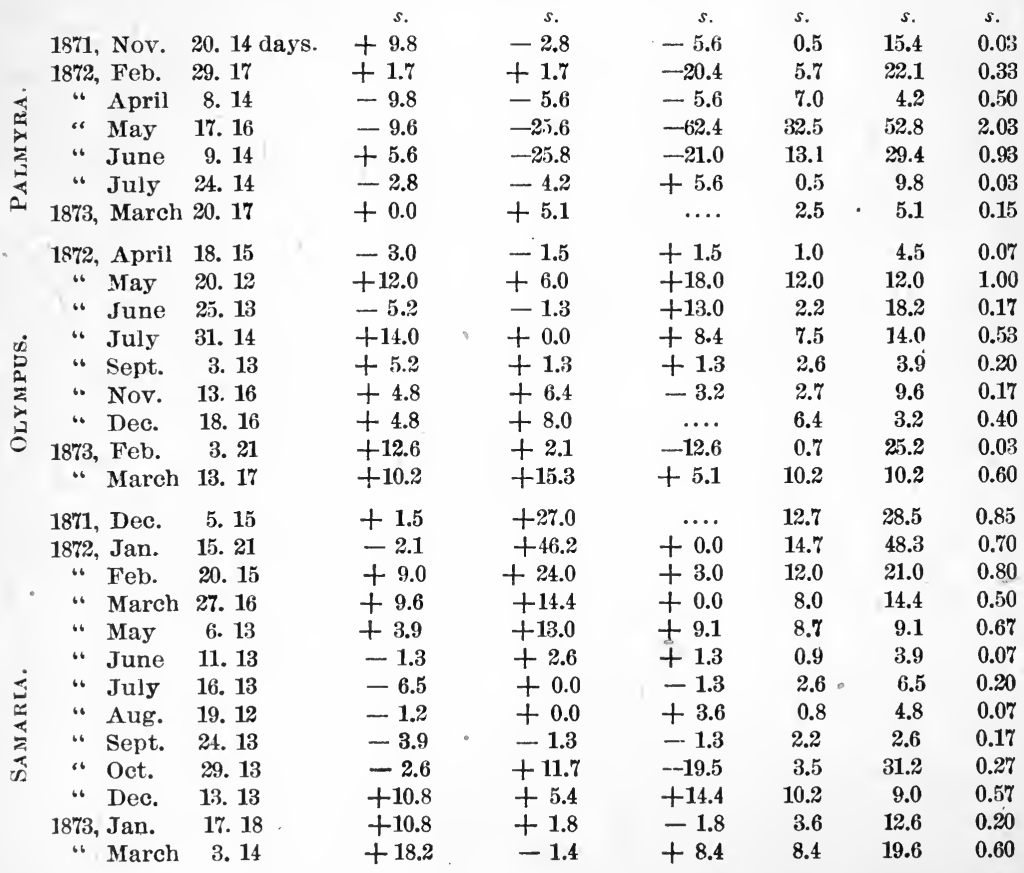




\section{Chronometer Rates on Cunard Steamers-Continued.} Steamer. Date of Length
arrival
at Boston. voyage. Chron. No. 1. Chron. No. 2. Chron. No. 3.

Mean Range Mean error of error error at end between of of Nos. I, 2 daily 造

1871. Nov. 27. 14 days. +5.6 1872. Feb. 5. 14

" March 29. 11

\section{1, Dec. 19. 15 \\ 1872, Feb. \\ 2. 18 \\ " March 14. 16 \\ , \\ 24. 14}

1872, Jan.

"April

17. 16

" June

29. 12

" July

4. 13

10. 14

ذ " Aug.

13. 13

'Sept.

17. 13

" Oct.

" Dec.

23. 14

5. 17

1873, Jan.

13. 21

"Feb.

1\%. 14

“ April

1. 15

1871, Des.

1872, Jall.

14. 15

" March

26. 18

"April

5. 15

¿ " " July

23. 13

28. 13

" Aug.

3. 14

"Sept.

" Oct.

5. 12

10. 13

"Nov.

" Dec.

1873, Feb.

“April

16. 14

20. 14

31. 22

7. 18

14. 12

1872, Jan.

3. 16

"Feb.

15. 17

$\begin{array}{lll}\$ & \text { March } \\ & & \\ & & \end{array}$

20. 16

25. 14

1873, Jan.

" Feb.

20. 14

"6 April

25. 15

7. 14

1872, Aug.

范 " " Nept.

29. 15

30. 12

7. 15

4. 19

"Feb.

12. 16

" March

\begin{abstract}
$+9.8$
$+3.3$
\end{abstract}

$$
\begin{array}{r}
+6.0 \\
-1.8 \\
+3.2 \\
+2.8 \\
+0.0 \\
-12.0 \\
-5.2 \\
-1.4 \\
+2.6 \\
-10.4 \\
-7.0 \\
-10.2 \\
-4.2 \\
+4.2 \\
-16.5
\end{array}
$$

$+31.5$

$+3.6$

$-9.0$

$-9.1$

$+2.6$

$-4.2$

$+6.0$

$-1.3$

$+5.6$

$-1.4$

$+2.2$

$+9.0$

$+1.2$

$+4.8$

$+18.7$

$-1.6$

$-1.4$

$-7.0$

$-4.5$

$-2.8$

$-12.0$

$-7.2$

$+3.0$

$-15.7$

$+0.0$

$-7.0$

\section{s.}

+4.2
+9.8

$-3.3$

$-1.5$

$+5.4$

$+22.4$

$-9.8$

$-1.6$

$+3.6$

$+2.6$

$+2.8$

$+16.9$

$+11.7$

$-1.4$

....

+25.2
-7.0

$-7.5$

$+4.5$

$+5.4$

$+1.5$

$-3.9$

$+0.0$

$+12.6$

$+4.8$

$+7.8$

$+11.2$

$+9.8$

…

$+0 . \hat{v}$

$-9.6$

$+3.2$

$+3.4$

$-9.6$

$+22.4$

$+5.6$

$+7.5$

$\begin{array}{r}+2.8 \\ \hline\end{array}$

$-4.5$

$-34.8$

$+0.0$

$+20.9$

$-25.6$

+1.4
+9.8
+8.8

$-1.5$

$+9.6$

$-8.4$

$-1.6$

$+2.4$

$-14.3$

$+18.2$

$+1.3$

$+10.4$

- 2.8

$-13.6$

$-14.7$

$+22.4$

$-3.0$

$+24.0$

$+16.2$

$+6.0$

$+0.0$

$+7.8$

$+4.2$

$+3.6$

$+3.9$

$\begin{array}{r}+9.8 \\ \hline\end{array}$

$-36.4$

$+4.4$

- 5.4

$-3.6$

$+3.2$

$+0.0$

$-6.4$

$+8.4$

$+4.5$

$+1.4$

$-63.0$

$-14$.

$+4.5$

+11 .

$+0.0$

$-2.8$
$-5.4$

$+8.4$

s.

\section{7}

9.8

2.7

\section{0}

0.6

11.7

5.1

1.1

2.0

5.6

$$
6.5
$$

\section{9}

3.9

3.7

11.9

\section{1}

6.5

9.0

$\begin{array}{rc}s . & s . \\ 4.2 & 0.26 \\ 0.0 & 0.70 \\ 12.1 & 0.26\end{array}$

7.5

10.8

19.2

12.6

1.6

15.60 .17

16.90 .43

19.60 .46

15.60 .53

22.10 .30

5.60 .26

$3.4 \quad 0.70$

$39.9 \quad 0.10$

$29.4 \quad 0.46$

13.50 .60

$20.0 \quad 27.0 \quad 1.33$

$\begin{array}{lll}8.4 & 12.6 & 0.47\end{array}$

$\begin{array}{lll}0.5 & 15.0 & 0.03\end{array}$

4.3

3.5

4.2

4.8

3.5

8.9

9.3

3.3

1.2

4.0

$9.1,0.33$

$\begin{array}{ll}7.8 & 0.27\end{array}$

16.80 .30

$2.4 \quad 0.40$

$9.1 \quad 0.27$

5.60 .63

$46.2 \quad 0.63$

$2.2 \quad 0.15$

$14.4 \quad 0.07$

$10.8 \quad 0.33$

\section{7}

$\begin{array}{ll}1.6 & 0.23\end{array}$ 


\section{Average Results.}

\begin{tabular}{|c|c|c|c|c|c|c|c|}
\hline Steamer. $\mathrm{v}$ & $\begin{array}{l}\text { No. of } \\
\text { voyages. }\end{array}$ & $\begin{array}{l}\text { Av. length } \\
\text { of voyage. }\end{array}$ & $\begin{array}{l}\text { Av. } \\
\text { Error of } \\
\text { daily } \\
\text { rate. }\end{array}$ & $\begin{array}{l}\text { Av. error } \\
\text { at end of } \\
\quad \text { of } \\
\text { voyage. }\end{array}$ & $\begin{array}{l}\text { Range between } \\
\text { greatest and } \\
\text { least value } \\
\text { of series. }\end{array}$ & $\begin{array}{c}\text { Range between } \\
\text { three } \\
\text { chronometers. }\end{array}$ & $\begin{array}{l}\text { Greatest } \\
\text { value } \\
\text { of series. }\end{array}$ \\
\hline & . & & s. & $s$. & $s$. & s. & s. \\
\hline Palmyra, & 7 & 14.7 days. & \pm 0.57 & 8.83 & 32.0 & 19.83 & 52.8 \\
\hline Olympus, & 9 & 15.2 & 0.35 & 5.03 & 11.3 & 11.20 & 25.2 \\
\hline Samaria, & 13 & 14.9 & 0.44 & 6.77 & 13.9 & 16.27 & 48.3 \\
\hline Hecla, & 11 & 14.7 & 0.37 & 5.29 & 10.8 & 16.65 & 39.9 \\
\hline Parthia, & 3 & 13.0 & 0.41 & 5.47 & 6.9 & 5.43 & 12.1 \\
\hline Tripoli, & 4 & 15.8 & 0.30 & 4.60 & 11.1 & 12.52 & 19.2 \\
\hline Siberia, & 13 & 14.9 & 0.40 & 5.84 & 19.5 & 13.77 & 46.2 \\
\hline Batavia, & 7 & 15.2 & 0.30 & 4.59 & 9.3 & 12.16 & 23.8 \\
\hline Malta, & 6 & 15.2 & 0.86 & 12.16 & 24.0 & 28.97 & 58.5 \\
\hline Means & 8 & 15.4 & 0.44 & 6.52 & 15.42 & 15.20 & 36.22 \\
\hline
\end{tabular}

Chronometer Rates on Sailing Vessels.

The chronometers in this discussion were selected without regard to rates, except when the variation exceeded 2 s., and the chronometers needed repairs at the end of the voyage. The materials for this part of the discussion were furnished by Mr. McConnell.

\begin{tabular}{|c|c|c|c|c|c|c|c|}
\hline Maker. & $\begin{array}{l}\text { No. of } \\
\text { chron. }\end{array}$ & $\begin{array}{l}\text { Length of } \\
\text { voyage }\end{array}$ & $\begin{array}{c}\text { Total er- } \\
\text { ror at } \\
\text { end of } \\
\text { voyage. } \\
s .\end{array}$ & Maker. & $\begin{array}{l}\text { No. of } \\
\text { chron. }\end{array}$ & $\begin{array}{l}\text { Length of } \\
\text { voyage. }\end{array}$ & $\begin{array}{c}\text { Total er- } \\
\text { ror at } \\
\text { end of } \\
\text { voyage. } \\
s .\end{array}$ \\
\hline \multirow[t]{10}{*}{ Bond \& Sons. } & 219 & 182 days. & 18.2 & \multirow[t]{10}{*}{ Bliss \& Creighton. } & 818 & 122 days. & 48.8 \\
\hline & 239 & 30 & 0.0 & & 1307 & 81 & 16.2 \\
\hline & 253 & 84 & 33.6 & & 1823 & 99 & 128.7 \\
\hline & 163 & 100 & 30.0 & & 878 & 64 & 64.0 \\
\hline & 173 & 71 & 0.0 & & 782 & 144 & 86.4 \\
\hline & 278 & 44 & 4.4 & & 1131 & 80 & 160.0 \\
\hline & 232 & 30 & 15.0 & & 1888 & 3 & 21.0 \\
\hline & 193 & 178 & 17.8 & & 2004 & 77 & 154.0 \\
\hline & 275 & 45 & 4.5 & & 1850 & 48 & 24.0 \\
\hline & 192 & 74 & 37.0 & & 815 & 82 & 32.8 \\
\hline \multirow[t]{10}{*}{ Hutton. } & 265 & 134 & 12.4 & \multirow[t]{10}{*}{ Negus. } & 1091 & 51 & 30.6 \\
\hline & 195 & 98 & 39.2 & & 709 & 93 & 46.5 \\
\hline & 492 & 78 & 7.8 & & 1151 & 31 & 15.5 \\
\hline & 366 & 147 & 44.1 & & 1000 & 107 & 21.4 \\
\hline & 218 & 81 & 5.4 & & 1178 & 88 & 88.0 \\
\hline & 351 & 141 & 42.3 & & 812 & 181 & 72.4 \\
\hline & 382 & 21 & 14.7 & & 1154 & 95 & 28.5 \\
\hline & 493 & 50 & 25.0 & & 848 & 44 & 11.4 \\
\hline & 289 & 20 & 12.0 & & 1048 & 55 & 16.5 \\
\hline & 160 & 40 & 12.0 & & 829 & 113 & 33.9 \\
\hline
\end{tabular}




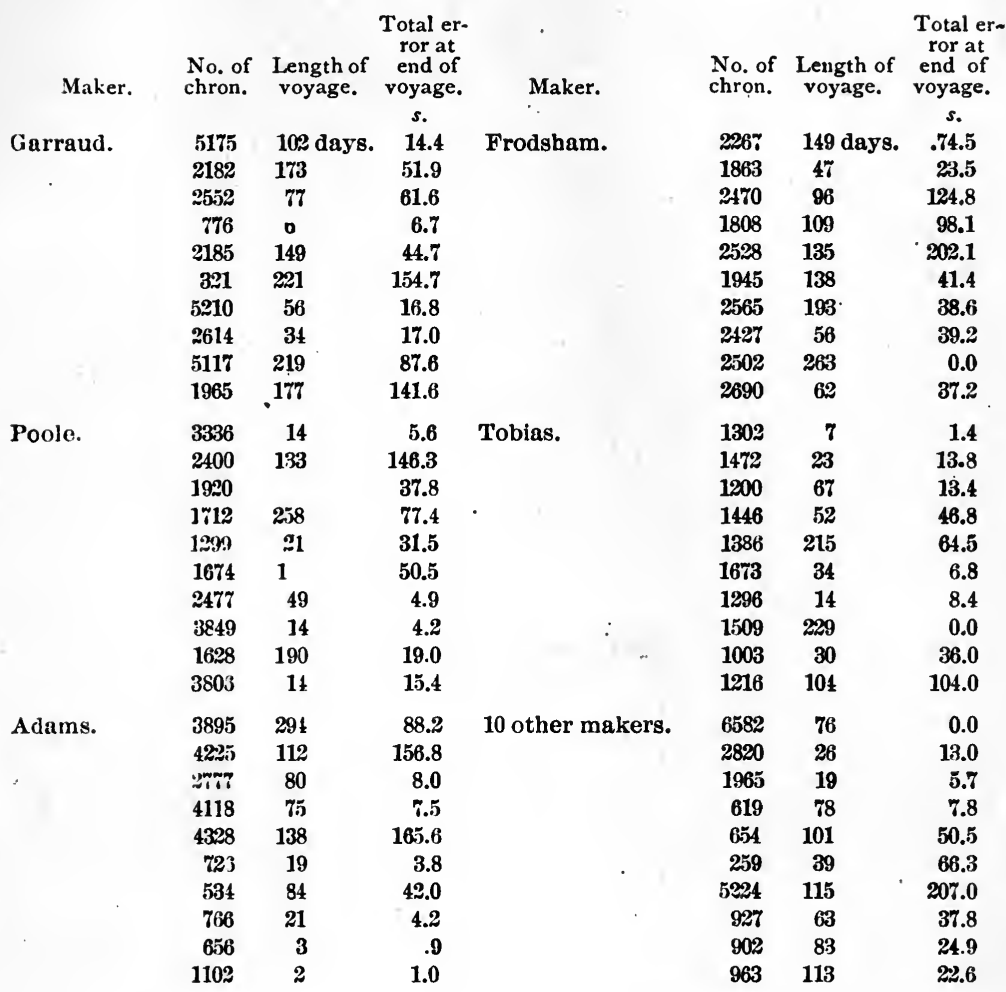

Collecting results, we have:

\begin{tabular}{lccc}
\multicolumn{1}{c}{ Maker. } & $\begin{array}{c}\text { Av. length of } \\
\text { voyage. }\end{array}$ & $\begin{array}{c}\text { Av.error of } \\
\text { daily rate. } \\
\text { B. }\end{array}$ & $\begin{array}{c}\text { Av. error a } \\
\text { of voyag }\end{array}$ \\
Bond \& Sons, & 84 days. & 0.19 & $s$. \\
Bliss \& Creighton, & 80 & 0.92 & 16.1 \\
Hutton, & 75 & 0.29 & 73.7 \\
Negus, & 86 & 0.42 & 21.6 \\
Berraud, & 127 & 0.47 & 36.5 \\
Frodsham, & 125 & 0.54 & 59.7 \\
Poole, & 98 & 0.40 & 67.9 \\
Tobias, & 78 & 0.38 & 39.3 \\
Adams, & 83 & 0.58 & 29.5 \\
10 other makers, & 71 & 0.61 & 47.8 \\
\multicolumn{1}{c}{ Means, } & 91 & 0.48 & 43.6 \\
\hline
\end{tabular}

The longitude expeditions undertaken by Professor Wm. C. Bond in 1849-50, and by Professor George P. Bond in 1855, for the accur- 
ate determination of the longitude between Cambridge and Greenwich, furnish the most reliable data available for a correct estimate of the degree of accuracy to be expected from the average performance of a chronometer during a short sea voyage. On these expeditions the rates of all the chronometers employed were carefully determined at each station.

In this discussion only those chronometers are selected which made three or more voyages. The longitude given by each chronometer is compared with $\lambda=4 \mathrm{~h} .44 \mathrm{~m} .30 .9 \mathrm{~s}$. The numbers given are current numbers, and not the numbers given to the chronometers by the makers. The values given under each number are the separate corrections to the assumed longitude given by the same chronometer on different voyages. The exceptional value of these determinations justifies the publication of the details.

ExPEDITION OF 1849-50.

\begin{tabular}{|c|c|c|c|c|c|c|c|c|c|c|c|}
\hline Nos. & 1 & 2 & 3 & 4 & 5 & 6 & 7 & 8 & 9 & 10 & 11 \\
\hline $\begin{array}{l}\text { Corrections by } \\
\text { each Chronometer } \\
\text { to assumed value } \\
\text { of } \lambda \text {. }\end{array}$ & $\begin{array}{c}8 . \\
+0.1 \\
+13.6 \\
+7.6\end{array}$ & $\begin{array}{r}8 . \\
+5.7 \\
+0.6 \\
+0.2\end{array}$ & $\begin{array}{c}8 . \\
+3.0 \\
-7.1 \\
-1.1\end{array}$ & $\begin{array}{l}8 . \\
+3.4 \\
+1.2 \\
+0.1\end{array}$ & $\begin{array}{r}8 . \\
+26.2 \\
+2.9 \\
+0.0 \\
-16.5 \\
+6.3 \\
+6.8 \\
\end{array}$ & $\begin{array}{r}8 . \\
+3.2 \\
+1.8 \\
+1.5\end{array}$ & $\begin{array}{r}8 . \\
+3.6 \\
-3.3 \\
-4.4\end{array}$ & $\begin{array}{r}8 . \\
+3.8 \\
+3.2 \\
+3.0\end{array}$ & $\begin{array}{r}8 . \\
-0.1 \\
-1.7 \\
+1.7\end{array}$ & $\begin{array}{r}8 . \\
+8.2 \\
+2.2 \\
-7.6\end{array}$ & $\begin{array}{r}s . \\
+0.1 \\
+1.4 \\
+1.9\end{array}$ \\
\hline Means .... & +1.97 & +2.17 & -1.73 & +1.57 & +2.18 & +3.17 & $-1.3 i$ & +1.87 & -0.03 & +0.93 & +1.13 \\
\hline \multirow{5}{*}{ Means.............. } & 12 & 13 & 14 & 15 & 16 & 17 & 18 & 19 & 20 & 21 & 22 \\
\hline & $\begin{array}{r}8 . \\
-7.4 \\
-15.3 \\
-14.8 \\
+10.6\end{array}$ & 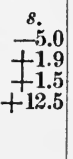 & $\begin{array}{r}8 . \\
+6.5 \\
-1.5 \\
-5.3\end{array}$ & $\begin{array}{r}8 . \\
-10.9 \\
-4.4 \\
-14.5\end{array}$ & $\begin{array}{r}8 . \\
+3.4 \\
+3.8 \\
+1.9\end{array}$ & $\begin{array}{r}8 . \\
-0.6 \\
-1.9 \\
+10.0 \\
-7.8 \\
+8.9\end{array}$ & $\begin{array}{r}8 . \\
-1.8 \\
-1.9 \\
+6.0 \\
-2.2 \\
+3.8\end{array}$ & $\begin{array}{r}8 . \\
0.3 \\
+10.5 \\
+11.7 \\
-6.1 \\
-10.9 \\
-12.8\end{array}$ & $\begin{array}{r}8 . \\
+11.0 \\
-5.8 \\
+5.5 \\
+0.6 \\
-0.9\end{array}$ & $\begin{array}{r}8 . \\
-12.9 \\
+15.5 \\
10.1 \\
+19.5 \\
+\quad 0.9 \\
+\quad 2.2\end{array}$ & $\begin{array}{r}8 . \\
+4.3 \\
+13.0 \\
+2.8 \\
-18.4 \\
-20.3 \\
+4.8\end{array}$ \\
\hline & -6.72 & +2.73 & -0.10 & {$[-9.93]$} & \multicolumn{2}{|c|}{$+3.03+1.72$} & +0.78 & -1.32 & \multicolumn{2}{|c|}{$+2.68++2.52$} & -2.30 \\
\hline & 23 & 24 & 25 & 26 & 27 & 28 & 29 & 30 & 31 & 32 & 33 \\
\hline & $\begin{array}{r}8 . \\
+7.1 \\
+13.8 \\
-8.3 \\
-6.1\end{array}$ & $\begin{array}{r}8 . \\
+2.9 \\
+5.9 \\
-1.4 \\
+9.0 \\
-12.5 \\
+9.1 \\
+3.1\end{array}$ & $\begin{array}{r}8 . \\
+2.9 \\
-3.3 \\
-11.7 \\
+10.7 \\
-4.2 \\
+1.7 \\
+9.3\end{array}$ & $\begin{array}{r}8.7 .5 \\
+76.0 \\
+16.0 \\
-10.4 \\
-39.0 \\
-11.7 \\
+1.4 \\
+1.2\end{array}$ & $\begin{array}{r}8 . \\
+6.1 \\
+8.5 \\
+20.1 \\
+4.0 \\
-34.5 \\
-5.0 \\
-9.0\end{array}$ & $\begin{array}{r}8 . \\
+4.3 \\
+14.6 \\
+3.9 \\
+8.8 \\
-8.5 \\
-1.0 \\
+5.2\end{array}$ & $\begin{array}{r}8 . \\
+0.1 \\
-7.1 \\
+5.8 \\
+16.5 \\
-6.7 \\
-5.0 \\
-5.3\end{array}$ & $\begin{array}{r}8 . \\
+0.9 \\
+10.1 \\
+5.1 \\
+5.9 \\
+0.1 \\
-6.5 \\
-5.1\end{array}$ & $\begin{array}{r}8 . \\
+4.0 \\
+15.5 \\
-3.6 \\
+8.3 \\
-13.5 \\
+0.1 \\
-15.0\end{array}$ & $\begin{array}{r}8 . \\
+2.3 \\
+12.5 \\
+11.4 \\
+10.9 \\
+0.8 \\
+1.0 \\
+5.4\end{array}$ & $\begin{array}{r}8 . \\
+15.2 \\
+14.0 \\
-14.0\end{array}$ \\
\hline Means............. & +1.88 & -0.30 & +0.77 & -5.00 & $|-3.83|$ & +2.78 & +1.78 & +1.50 & -0.60 & +2.41 & +0.33 \\
\hline
\end{tabular}


THE COEFFICIENT OF SAFETY IN NAVIGATION.

Expedition of 1855.

\begin{tabular}{|c|c|c|c|c|c|c|c|c|c|c|c|c|}
\hline Nos. & 1 & 2 & 3 & 4 & 5 & 6 & 7 & 8 & 9 & 10 & 11 & 12 \\
\hline \multirow{5}{*}{$\begin{array}{c}\text { Correcti'ns } \\
\text { by each } \\
\text { Chronome- } \\
\text { ter to } \\
\text { nssumed } \\
\text { value of } \lambda . \\
\text { Means..... }\end{array}$} & $\begin{array}{r}8 . \\
+2.8 \\
\mathbf{f}^{0.9} \\
\mathbf{- 5 . 7} \\
\mathbf{+ 1 . 9} \\
\mathbf{+ 0 . 9}\end{array}$ & $\begin{array}{r}8 . \\
+1.8 \\
-4.2 \\
+3.2 \\
-1.9\end{array}$ & $\begin{array}{r}8 . \\
-15.8 \\
-2.4 \\
-5.9 \\
+0.3 \\
-4.5 \\
-1.1\end{array}$ & 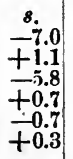 & $\begin{array}{l}8 . \\
+3.5 \\
-0.2 \\
-0.1 \\
-0.7 \\
-6.4 \\
-5.9\end{array}$ & $\begin{array}{c}8 . \\
-0.2 \\
-5.1 \\
-1.9 \\
+2.4 \\
-0.7 \\
-0.6\end{array}$ & $\begin{array}{r}8 . \\
-12.5 \\
-2.0 \\
-4.8 \\
+0.8 \\
-2.5 \\
-0.5\end{array}$ & $\begin{array}{r}8.9 \\
+2.9 \\
+0.4 \\
-0.9 \\
+0.1 \\
+1.0\end{array}$ & \begin{tabular}{c|}
8. \\
-6.1 \\
-2.7 \\
-1.4 \\
-1.8 \\
-3.6 \\
-0.8
\end{tabular} & $\begin{array}{r}8.9 \\
-3.00 \\
+1.4 \\
-5.1 \\
-8.9 \\
-3.2 \\
+2.8\end{array}$ & \begin{tabular}{r|}
8. \\
$-46.2)$ \\
+5.5 \\
-8.5 \\
-7.7 \\
-4.3 \\
+2.7
\end{tabular} & $\begin{array}{r}8 . \\
-59.2) \\
-3.8 \\
-0.6 \\
-5.3 \\
-2.4 \\
+1.7\end{array}$ \\
\hline & +3.04 & -0.27 & -4.90 & -1.90 & -1.63 & -1.02 & -3.58 & -0.88 & -2.73 & -2.60 & -2.42 & -2.08 \\
\hline & 13 & $14^{\circ}$ & 15 & 16 & 17 & 18 & 19 & 20 & 21 & 22 & 23 & 24 \\
\hline & $\begin{array}{c}8 . \\
-6.2 \\
-0.2 \\
-4.4 \\
+6.0 \\
-4.2 \\
+2.6\end{array}$ & $\begin{array}{r}8 . \\
+1.8 \\
+4.9 \\
+2.5 \\
-1.2 \\
+2.2 \\
-1.4\end{array}$ & $\begin{array}{r}8 . \\
-2.6 \\
-4.8 \\
+0.7 \\
-0.5 \\
+2.3 \\
-6.3\end{array}$ & $\begin{array}{r}8 . \\
-0.6 \\
-1.4 \\
+_{0.3}^{0.3} \\
\pm_{1.8} \\
+1.7\end{array}$ & 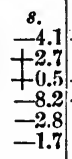 & $\begin{array}{r}8 . \\
-11.2 \\
+1.9 \\
+11.2 \\
+1.2 \\
-4.8 \\
+3.9\end{array}$ & $\begin{array}{r}8 . \\
-11.7 \\
+5.8 \\
-1.6 \\
-2.4 \\
+2.4\end{array}$ & $\begin{array}{r}8 . \\
+8.7 \\
-0.8 \\
-1.5 \\
+8.5 \\
-1.2 \\
+1.2\end{array}$ & $\begin{array}{r}8 . \\
f^{8} 0.0 \\
-0.5 \\
-5.4 \\
+3.4 \\
-5.1 \\
-11.1\end{array}$ & $\begin{array}{l}8 . \\
-1.0 \\
-5.3 \\
-4.0 \\
+0.0 \\
+2.4 \\
+3.4\end{array}$ & $\begin{array}{r}8 . \\
+1.1 \\
+0.8 \\
+10.8 \\
-4.1 \\
+0.1 \\
-0.3\end{array}$ & $\begin{array}{l}8 . \\
-1.3 \\
-5.5 \\
-2.4 \\
-2.3 \\
-3.3 \\
-1.5\end{array}$ \\
\hline & -1.07 & +1.47 & -1.87 & +0.35 & -2.27 & -1.57 & -1.67 & +2.48 & -1.15 & -1.88 & +1.13 & -2.75 \\
\hline $\operatorname{ans}$ & 25 & 26 & 27 & 28 & 29 & 30 & 31 & 32 & 33 & 34 & 35 & $3 \varsigma$ \\
\hline \multirow{4}{*}{$\begin{array}{c} \\
. \\
. . \\
\text { Means..... }\end{array}$} & $\begin{array}{r}8 . \\
+0.5 \\
+2.6 \\
+1.5 \\
-1.0 \\
+1.5 \\
-0.7 \\
\end{array}$ & $\begin{array}{r}8 . \\
+3.4 \\
-0.4 \\
-0.2 \\
-4.7 \\
-1.1\end{array}$ & $\begin{array}{r}8.0 \\
+0.0 \\
-0.9 \\
-0.2 \\
-0.8 \\
-0.7 \\
-1.2\end{array}$ & $\begin{array}{r}8 . \\
+0.3 \\
-6.4 \\
-2.8 \\
-4.2 \\
+0.0 \\
-4.6 \\
\end{array}$ & $\begin{array}{c}8 . \\
-7.9 \\
-3.7 \\
-6.3 \\
=-0.3 \\
-1.5 \\
-0.9\end{array}$ & \begin{tabular}{r|}
8. \\
-3.1 \\
-9.8 \\
+0.1 \\
+4.7 \\
+0.5 \\
+5.2
\end{tabular} & $\begin{array}{r}8 . \\
-5.8 \\
-0.1 \\
-4.8 \\
+7.6 \\
+6.5 \\
+11.9 \\
\end{array}$ & $\begin{array}{c}8 . \\
-3.1 \\
-0.2 \\
-2.5 \\
+0.5 \\
-1.8 \\
-2.1 \\
\end{array}$ & $\begin{array}{r}8 . \\
-16.4 \\
+4.8 \\
+10.6 \\
-0.4 \\
+0.2 \\
+1.1 \\
\end{array}$ & $\begin{array}{r}8 . \\
+7.0 \\
+1.9 \\
+4.7 \\
+10.1 \\
+5.2 \\
+4.3\end{array}$ & $\begin{array}{r}8 . \\
-0.2 \\
+1.9 \\
-4.1 \\
-0.6 \\
+3.5 \\
-0.8 \\
\end{array}$ & $\begin{array}{r}8 . \\
+7.6 \\
+5.9 \\
+4.8 \\
+5.8 \\
-0.5 . \\
+1.6\end{array}$ \\
\hline & -0.13 & -0.60 & -0.63 & -2.95 & -3.28 & -0.40 & +0.38 & -1.53 & -3.55 & -0.20 & -0.05 & +2.23 \\
\hline & 37 & 38 & 39 & 40 & 41 & 42 & 43 & 41 & 45 & 46 & 47 & 48 \\
\hline & $\begin{array}{r}8 . \\
+5.0 \\
+0.1 \\
-3.8 \\
-1.2 \\
-2.7\end{array}$ & $\begin{array}{r}8.1 .4 \\
+2.2 \\
-4.1 \\
-0.5 \\
-2.5\end{array}$ & $\begin{array}{r}8.1 .5 \\
-3.4 \\
+0.5 \\
+3.9 \\
+3.0\end{array}$ & $\begin{array}{c}8 . \\
-3.0 \\
-1.5 \\
+0.9\end{array}$ & $\begin{array}{c}8 . \\
-4.9 \\
-1.3 \\
-0.2\end{array}$ & $\begin{array}{c}8 . \\
-7.2 \\
-0.2 \\
-0.4\end{array}$ & $\begin{array}{c}8 . \\
-\mathrm{i} .7 \\
-2.2 \\
-2.5\end{array}$ & $\begin{array}{r}8 . \\
+6.2 \\
-0.4 \\
-5.7\end{array}$ & \begin{tabular}{c|}
8. \\
-14 \\
-0.6 \\
-1.2
\end{tabular} & $\begin{array}{l}8 . \\
-7.1 \\
+9.8 \\
-3.5 \\
-6.2 \\
-1.8 \\
+2.1\end{array}$ & $\begin{array}{l}8 . \\
+4.6 \\
-3.1 \\
-2.3 \\
+6.4 \\
-4.0 \\
+1.0\end{array}$ & $\begin{array}{l}8 . \\
-3.0 \\
-1.2 \\
-9.0 \\
-3.3 \\
+2.8 \\
-3.1\end{array}$ \\
\hline Means ..... & -0.52 & -1.26 & -1.06 & 1.2 & -2.1 & $-2.6 n$ & 2.13 & +0.03 & -1.07 & -1.12 & +043 & -2.80 \\
\hline
\end{tabular}


Combining the mean corrections given by each chronometer on different voyages, without regard to weights, we have the following results:

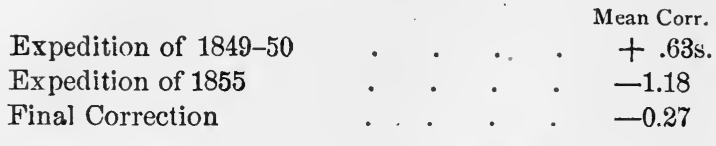

In order to form an estimate of the liability to error in any chronometer, we must compare the greatest and the least corrections given by the same chronometer on different voyages. The average range for $1849-50$ is $19.5 \mathrm{~s}$., and for 1855 it is $10.8 \mathrm{~s}$. The extreme range is shown in the following table:

$\begin{array}{cccccccccccc}s & s & s & s & s & s & s & s & s & s & s & s \\ \text { Limits } 55 & 50 & 45 & 40 & 35 & 30 & 25 & 20 & 15 & 10 & \mathbf{5} & 0 \\ \cdots & \text { to } & \text { to } & \text { to } & \text { to } & \text { to } & \text { to } & \text { to } & \text { to } & \text { to } & \text { to } & \text { to } \\ \text {. } & \mathbf{5 5} & 50 & 45 & 40 & 35 & 30 & \mathbf{2 5} & 20 & \mathbf{1 5} & \mathbf{1 0} & \mathbf{5}\end{array}$

$\begin{array}{lllllllllllr}\text { Expedition } \\ { }_{1849-50 .} \text { Number of Cases. } \\ { }_{1855 .} & 2 & 0 & 1 & 0 & 4 & 1 & 8 & 4 & 4 & 4 & 5 \\ 0 & 1 & 0 & 1 & 1 & 0 & 0 & 2 & 6 & 8 & 19 & 10\end{array}$

The values given on pages 370 and 371 represent absolute corrections from which the error of rate has been eliminated. It is not possible, therefore, to determine the average error of the daily rate directly from these series. It can be obtained, however, somewhat indirectly from the table given on page 368. It appears from this table that the average range between the greatest and the least values of the average errors at the end of a voyage of 14.8 days is $15.42 \mathrm{~s}$., and that the coefficient by which this average error must be multiplied in order to produce the latter value is $2.3 \%$. The mean of the average range for the expedition for $1849-50$ and that for 1855 is $15.2 \mathrm{~s}$., from which we may with tolerable safety assume the average error at the end of a voyage of 15 days to be not far from 6.4s., giving for the average daily crror of rate the value $\pm 0.43 \mathrm{~s}$, which is almost idlentical with the values already found on pages 370 and 371 .

I add, without details, the results of two other longitude expeditions:

Cambridge, New York and Chagres

Eclipse Expedition to Labrador

$\begin{array}{cc}\begin{array}{c}\text { No. of } \\ \text { Chronome- } \\ \text { ters. }\end{array} & \begin{array}{c}\text { Length } \\ \text { of } \\ \text { Voyage. } \\ \text { Days. }\end{array} \\ & \end{array}$

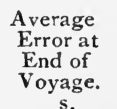

Range be- Coeff. tween greatest and leas
Value. s. 
Here we have from a limited number of observations the value $\pm 0.41 \mathrm{~s}$. for the average error of the daily rate.

It must be remembered that the results so far obtained are avercuge results obtained from a large number of observations made under the most favorable conditions. They indicate that a chronometer of average quality is at any time liable to change its daily rate by an amount as great as $0.5 \mathrm{~s}$. 'That this value is probably too small will appear from the following table given by Mr. Hartnup, who made the investigation in 1863. The quantities given represent the error at the end of a voyage of the given duration.

\begin{tabular}{|c|c|c|c|c|c|c|c|c|c|c|c|}
\hline 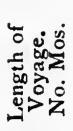 & 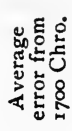 & $\begin{array}{c}\text { Best } \\
10 \\
\text { in } \\
100 .\end{array}$ & $\begin{array}{c}2 \mathrm{~d} \text { best } \\
\text { ro } \\
\text { in } \\
\text { 10o. }\end{array}$ & $\begin{array}{c}3 \mathrm{~d} \text { best } \\
\text { 10 } \\
\text { in } \\
\text { 10o. }\end{array}$ & $\begin{array}{c}4^{\text {th best }} \\
10 \\
\text { in } \\
100 .\end{array}$ & $\begin{array}{l}5^{\text {th }} \text { best } \\
\text { 10 } \\
\text { in } \\
\text { 100. }\end{array}$ & $\begin{array}{c}6 \text { th best } \\
\text { 10 } \\
\text { in } \\
100 .\end{array}$ & $\begin{array}{c}\text { 7th best } \\
\text { ro } \\
\text { in } \\
\text { 10o. }\end{array}$ & $\begin{array}{c}8 \text { th best } \\
\text { ro } \\
\text { in } \\
100 .\end{array}$ & $\begin{array}{c}9 \text { th best } \\
\text { io } \\
\text { in } \\
100 .\end{array}$ & $\begin{array}{c}\text { Worst } \\
\text { Io } \\
\text { in } \\
\text { xoo. }\end{array}$ \\
\hline $\begin{array}{r}1 \\
2 \\
3 \\
4 \\
45 \\
6 \\
7 \\
8 \\
9 \\
10 \\
11 \\
12\end{array}$ & $\begin{array}{c}\text { Miles. } \\
\mathbf{6} \\
14 \\
23 \\
33 \\
44 \\
56 \\
69 \\
82 \\
95 \\
108 \\
122 \\
136\end{array}$ & $\begin{array}{c}\text { Miles. } \\
\mathbf{0} \\
\mathbf{0} \\
\mathbf{1} \\
\mathbf{1} \\
\mathbf{1} \\
\mathbf{2} \\
\mathbf{2} \\
\mathbf{3} \\
\mathbf{3} \\
4 \\
4 \\
\mathbf{5}\end{array}$ & \begin{tabular}{|c} 
Miles. \\
1 \\
$\frac{1}{2}$ \\
3 \\
4 \\
5 \\
5 \\
6 \\
8 \\
10 \\
12 \\
14 \\
16 \\
18
\end{tabular} & $\begin{array}{c}\text { Miles. } \\
1 \\
4 \\
6 \\
8 \\
10 \\
13 \\
16 \\
19 \\
22 \\
2 \beta \\
30 \\
34\end{array}$ & $\begin{array}{c}\text { Miles. } \\
\mathbf{2} \\
\mathbf{5} \\
\mathbf{9} \\
13 \\
17 \\
21 \\
25 \\
30 \\
35 \\
40 \\
46 \\
\mathbf{5 2}\end{array}$ & \begin{tabular}{|c} 
Miles. \\
3 \\
3 \\
7 \\
12 \\
17 \\
22 \\
28 \\
34 \\
41 \\
48 \\
56 \\
64 \\
72
\end{tabular} & $\begin{array}{c}\text { Miles. } \\
4 \\
4 \\
9 \\
15 \\
22 \\
29 \\
37 \\
46 \\
55 \\
65 \\
75 \\
86 \\
97\end{array}$ & $\begin{array}{c}\text { Miles. } \\
\mathbf{5} \\
11 \\
18 \\
28 \\
39 \\
50 \\
62 \\
74 \\
86 \\
98 \\
111 \\
124\end{array}$ & $\begin{array}{c}\text { Miles. } \\
7 \\
75 \\
25 \\
25 \\
36 \\
19 \\
64 \\
80 \\
98 \\
117 \\
1137 \\
157 \\
178\end{array}$ & \begin{tabular}{|c|} 
Miles. \\
9 \\
29 \\
24 \\
41 \\
61 \\
84 \\
108 \\
134 \\
159 \\
184 \\
208 \\
233 \\
258
\end{tabular} & $\begin{array}{c}\text { Miles. } \\
25 \\
25 \\
62 \\
101 \\
143 \\
187 \\
233 \\
280 \\
328 \\
376 \\
425 \\
474 \\
524\end{array}$ \\
\hline
\end{tabular}

An error of 524 miles in a ship's position may seem to be rather too large an estimate, but Lord Anson, in a voyage around Cape Horn, did better than this. One of his ships was 500 miles out of her reckoning, and one actually made land on the wrong side of pthe continent, the error of position being over 600 miles.

In $1871 \mathrm{Mr}$. Hartnup made an additional investigation, obtaining the following results:

Extreme Difference Variation of daily Mean of extreme of mean daily rate rate due to change difference between between any 2 weeks of temperature. any 2 days of each

Mean from 297 chronometers

Mean from 40 poorest

Mean excluding 40 poorest

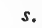

2.19

6.28

1.56
1.73

4.55

1.29 week.

s.

0.98

2.80

0.70

In order to show how largely chronometer errors may be diminished when the rate is given for different temperatures in the form adopted 
by Mr. Hartnup, I add the following table, given by him in this connection, derived from the actual performance of a given chronometer:

Mean Daily Rate.

\begin{tabular}{|c|c|c|c|c|}
\hline \multicolumn{2}{|l|}{ Date. } & Temp $=55^{\circ}$. & Temp $=70^{\circ}$. & Temp. $=85^{\circ}$ \\
\hline A pril, & 1867 & $-0^{s}$ & $+\stackrel{s}{1.4}$ & $+\stackrel{s}{2.3}$ \\
\hline May, & 1868 & -0.6 & +1.4 & +2.2 \\
\hline April, & 1869 & -1.4 & +1.7 & +2.7 \\
\hline November & 1869 & -0.2 & +1.9 & +2.8 \\
\hline February, & 1871 & -0.2 & +1.5 & +2.3 \\
\hline
\end{tabular}

From the first column of Mr. Hartnup's first table I deduce the following values for the error of the daily rate. from the mean of 1700 chronometers, assuming the months to be calendar months:

$\begin{array}{cccc}\text { No. months. } & \begin{array}{c}\text { Average error } \\ \text { of daily rate. }\end{array} & \text { No. months. } & \begin{array}{c}\text { Average error } \\ \text { of daily rate. }\end{array} \\ 1 & \pm 0.80 & 7 & s \\ 2 & 0.93 & 8 & 1.31 \\ 3 & 1.02 & 9 & 1.37 \\ 4 & 1.10 & 10 & 1.41 \\ 5 & 1.17 & 11 & 1.44 \\ 6 & 1.24 & 12 & 1.48 \\ & & 1.51\end{array}$

I am not sure that I have given the correct interpretation to Mr. Hartnup's values, since it is difficult to understand why the error should increase with the time.

From Mr. Hartnup's second table we have the value $\pm 0.98 \mathrm{~s}$. Adopting the mean between the latter value and $\pm 0.46 \mathrm{~s}$, the value derived from this discussion, we have finally $\pm 0.72 \mathrm{~s}$. as the average daily error of the rate of an average chronometer.

The average coefficient of safety for chronometer errors only derived from this discussion is 3.2. If, therefore, the navigator has a chronometer of average excellence, he must at the end of twenty days expect from it an average error of 3.6 miles, and he must look out for an error of $3.6 \mathrm{~m} . \times 3.2$, or 11.5 miles.

It must be borne in mind that these results are independent of the errors of observation with the sextant, which are still to be added.

In estimating the limits within which it is possible to locate the position of a ship at sea by astronomical observations, it is necessary to take into account all the errors to which such observations are liable. I shall consider only the method usually employed, viz. the measurement of the altitude of the sun with a sextant at a given time 
before it comes to the meridian for longitude, and the measurement of its altitude at culmination for latitude.

First of all we must estimate the magnitude of the errors to which sextant observations are liable.

They are as follows:

(a) Instrumental errors, such as excentricity, errors of graduation, index error, \&c. In a first-class sextant errors of this class often exceed one minute of arc.

(b) Error in noting the time. No observer at sea pretends to note the time closer than 1s. In fact it is impossible for him to do so. If we assume the low limit of $1 \mathrm{~s}$. and multiply by the, coefficient 3.5 we find an error from this source amounting to nearly one mile.

(c) Error arising from an imperfect sea-horizon. I am convinced that errors from this cause may amount to several miles. In a series of observations made to test the value of Lieut. Beecher's artificial horizon, the range of error was six miles. Nor does the use of an artificial horizon mend the matter, for there is always an undetermined constant between the two methods which ranges from two to eight miles.

(d) Errors arising from the use of approximate data. It is almost universally the practice to take data to the nearest minute of arc, e. $g$. it is the practice to take the sun's diameter as $30^{\prime}$. Many navigators lump all corrections together and call the sum $12^{\prime}$. The error from this source may amount to no less than five miles. Another source of error is the failure to use the value of the refraction corresponding with the actual condition of the atmosphere indicated by the thermometer and barometer at the time of observation. The only observations which I can find bearing upon this point were made by Commander Bayfield at Quebec in 1832, the thermometer reading $11^{\circ}$ Fahrenheit. He found that the error arising from the use of the mean instead of the actual refractions amounted to three miles.

(e) Errors affecting the longitude which depend upon the latitude of the ship and upon the declination and the observed altitude of the sun. The errors arising from this source may be much larger than is generally suspected, and they are the more important because, for the most part, they escape the attention of the navigator. 
Let,

$A=$ the observed altitude of the sun.

$\delta=$ the declination of the sun.

$\varphi=$ the latitude of the place of observation.

$\theta=$ the observed hour angle.

$\eta=$ the observed azimuth.

$\psi=$ the angle at the sun.

From the triangle

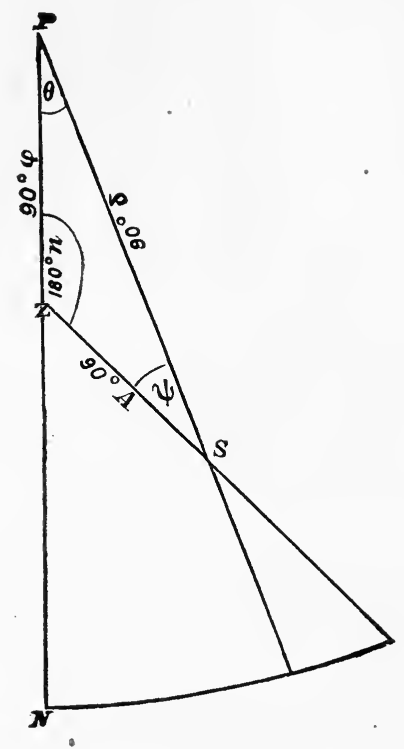

We obtain

$$
\sin . \frac{1}{2} 0=\sqrt{\frac{\sin \cdot\left(s-\left(90^{\circ}-\delta\right)\right) \sin .\left(s-\left(90^{\circ}--\varphi\right)\right)}{\cos . j \cos . \varphi}}
$$

where

$$
\begin{aligned}
& s=\frac{1}{2}\left[\left(90^{\circ}-\delta\right)+\left(90^{\circ}-A\right)+\left(90^{\circ}-\varphi\right)\right] \\
& \sin . \zeta^{\prime}=\frac{\sin . \theta \cos . \varphi}{\cos . A}=\frac{\cos . \varphi \sin . \eta}{\cos . \delta} \\
& \sin . \gamma_{i}=\frac{\sin . \theta \cos . i}{\cos . A} \text {. }
\end{aligned}
$$


In order to compute the values of the various errors which may affect $\theta$, we differentiate the gencral equation :

$\sin . A=\sin . \varphi \sin . \delta+\cos . \varphi \cos . \delta \cos . \theta$.

From which

$\cos . A d A=(\sin . \varphi \cos . \delta-\cos . \varphi \sin . \delta \cos . \theta) d \delta$ $+(\sin . \delta \cos . \varphi-\cos . \delta \sin . \varphi \cos . \theta) d \varphi$

But - cos. $\varphi$ cos. $\delta$ sin. $\theta d \theta$.

$\cos . \delta \sin . \varphi-\sin . \delta \cos . \varphi \cos . \theta=\cos . A \cos . \zeta^{\prime \prime}$ sin. $\delta \cos . \varphi-\cos . \delta \cos . \theta$ sin. $\varphi=-\cos . A \cos . \eta$ cos. $\varphi \sin . \theta=\cos . A \sin . \zeta^{\prime \prime}$.

By substitution we casily find:

$$
d 0=-\frac{d A}{\cos \varphi \sin . \eta}+\frac{d \delta}{\cos . \delta \text { tang. } \zeta^{\prime \prime}}-\frac{d \varphi}{\cos \varphi \operatorname{tang} . \eta}
$$

In the proceedings of the American Association for 1881, p. 154, Mr. S. C. Chandler has given the following convenient form to this equation :

Dividing both members of the equation,

$$
\text { cos. } \delta \sin . \psi^{\prime}=\cos . \varphi \sin . \eta
$$

by cos. $\varsigma^{\prime}$, we have :

$$
\text { cos. } \delta \text { tang. } \psi^{\prime}=\frac{\cos . \varphi \sin . \eta}{\cos . \psi}
$$

whence $\quad d \theta=\frac{1}{\cos . \varphi \sin . \eta}\left[\cos . \varphi^{\prime} d \delta-d A-\cos . \eta d \varphi\right]$.

From this equation it appears :

(1) That the effect of an error in the observed altitude upon the time will be minimum when $\varphi=0^{\circ}$ and $\eta_{1}=90^{\circ}$, or when the sum is in the prime vertical.

(2) That the effect of an error in $\delta$ will be minimum when $\delta=0^{\circ}$. and $\psi^{\prime \prime}=90^{\circ}$.

(3) That the effect of an error in $\varphi$ will be minimum when $\varphi=0^{\circ}$ and $r_{\gamma}=90^{\circ}$.

As an example we will assume that in a given observation of the sun or of a star the following small errors have been made, viz. :

$$
\begin{aligned}
d \varphi & =+1^{\prime} \\
d A & =+1^{\prime} \\
d s & =-1^{\prime} .
\end{aligned}
$$


We compute the effect of these errors upon $\theta$ in three assumed cases :

$$
\begin{aligned}
& \text { I. II. III. } \\
& \varphi=39^{\circ} 54^{\prime} \quad 51^{\circ} 30^{\prime} \quad 70^{\circ} 0^{\prime} \\
& \delta=+17^{\circ} 29^{\prime} \quad-6^{\circ} 37^{\prime} \quad+44^{\circ} 0^{\prime} \\
& A=15^{\circ} 54^{\prime} \quad 13^{\circ} 40^{\prime} \quad 63^{\circ} 30^{\prime} \\
& 0=83^{\circ} 37^{\prime} \quad 58^{\circ} 8^{\prime} . \quad 10^{\circ} 10^{\prime} \\
& n=80^{\circ} 16^{\prime} \quad 60^{\circ} 15^{\prime} \quad 16^{\circ} 32^{\prime} \\
& \psi^{\prime}=52^{\circ} 26^{\prime} \quad 32^{\circ} 58^{\prime} \quad 7^{\circ} 46^{\prime} \\
& -\frac{d A}{\cos \varphi \sin . \eta}=-1.32^{\prime} \quad-1.85^{\prime} \quad-10.27^{\prime} \\
& -\frac{d \varphi}{\cos \varphi \text { tang. } \gamma_{i}}=-0.22^{\prime} \quad-0.92^{\prime} \quad-9.85^{\prime} \\
& +\frac{d \delta}{\cos . \delta \text { tang. } \iota^{\prime \prime}}=-0.81^{\prime} \quad-1.55^{\prime} \quad-10.19^{\prime}
\end{aligned}
$$

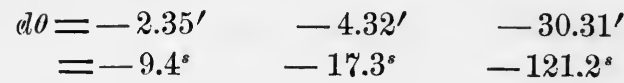

Ordinarily there will be some elimination between $d \varphi, d A$ and $d \delta$, but the errors may all act in the same direction, as in the examples given. The third example may perhaps be considered an extreme case, but it will serve to show the necessity of a computed table of coefficients which shall serve as a guide in estimating the value of any given observation. An appropriate name for them would be locul coefficients of safety.

$(f)$ Errors arising from the error in the estimated run of the ship between the morning and the noon observations. The morning or afternoon observations give one co-ordinate of position, viz. the longitude; and the noon observations, the other, viz. the latitude. To get both co-ordinates for the same instant requires an allowance for the run of the ship during the intervening time. It is impossible to give any definite estimate of the magnitude of the errors thus introduced, but I suspect they will in general be found to exceed all the other errors combined.

In order to determine the degree of accuracy which may be expected from the sextant considered as an instrument of observation, when used by trained and skillful observers, I have collected such observations of this class as were available, both for time and for latitude. In most cases the average error has been found by comparison of the observations inter se. 'The observations made at Willet's Point have 
an exceptional value, since they were compared with transit observa-

- tions made at nearly the same time.

\section{Fror Latitude.}

\begin{tabular}{|c|c|c|c|c|c|}
\hline Obser & $\begin{array}{l}\text { Place of } \\
\text { Observation. }\end{array}$ & $\begin{array}{l}\text { Average } \\
\text { Error. }\end{array}$ & & $\begin{array}{l}\text { Range of } \\
\text { Error. }\end{array}$ & Coeff. \\
\hline Williams, & 1793....Cambridge ......... & $3.6^{\prime \prime}$ & & $14^{\prime \prime}$ & 3.5 \\
\hline \multirow{10}{*}{ Paine, } & $1831 . .$. Norfolk, Va.......... & 9.6 & & 40 & 4.2 \\
\hline & Richmond.......... & 7.2 & & 31 & 4.3 \\
\hline & Washington......... & 4.6 & & 18 & 3.9 \\
\hline & Baltimore........... & 5.0 & & 20 & 4.0 \\
\hline & Providence.......... & 10.1 & ' & 50 & 5.0 \\
\hline & Washington Territory. & 7.2 & & 46 & 6.4 \\
\hline & " & 10.9 & & 41 & 3.8 \\
\hline & 1869.... Willet's Point ....... & 7.0 & & 24 & 3.4 \\
\hline & $1871 \ldots$ & 7.8 & & 29 & 3.7 \\
\hline & $1872 \ldots$ & 9.0 & & 35 & 3.9 \\
\hline \multicolumn{2}{|c|}{ Hall and Tupman.Malta ............ } & 10.5 & & 59 & 5.6 \\
\hline \multicolumn{2}{|r|}{ “ } & 10.2 & & 37 & 3.6 \\
\hline & “ & 8.0 & & 34 & 4.2 \\
\hline & 5.0 & & 30 & 6.0 \\
\hline \multicolumn{2}{|c|}{ Hall and Tupman. Syracuse $\ldots \ldots \ldots \ldots \ldots$} & 9.2 & & 36 & 3.9 \\
\hline \multicolumn{2}{|r|}{. “ } & 7.7 & & 56 & 7.3 \\
\hline \multicolumn{2}{|r|}{ “ } & 7.1 & & 28 & 3.9 \\
\hline \multicolumn{2}{|r|}{ “ } & 6.8 & & 28 & 4.1 \\
\hline \multicolumn{2}{|r|}{ “ } & 6.7 & & 30 & 4.5 \\
\hline \multicolumn{2}{|c|}{ Harkness.......... Des Moines ......... } & 6.4 & & 47 & 7.3 \\
\hline & ns... & $7.6^{\prime \prime}$ & & $35^{\prime \prime}$ & 4.6 \\
\hline
\end{tabular}

For Time.

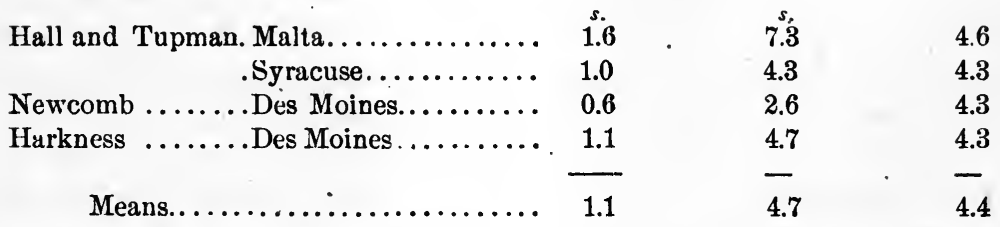

For the mean of any number of observations with the sextant, therefore, we must expect an average error of $7.6^{\prime \prime}$ in latitude and of 1.1s. in lnngitude, and the average liability to error of a single observation will be about $35^{\prime \prime}$ in latitude and $4.7 \mathrm{~s}$. in longitude. For sea observations an additional coefficient of 3 units will be none too great. No instrument of precision is so liable to constant errors as 
the sextant. In all the cases given above these constant errors were thoroughly investigated and the resulting corrections were applied. It is not to be expected that this can be done with sextants used at sea. Even with observations on shore this instrument often acts in a most perverse and unaccountable way. The observations of Williams for the determination of the latitude of Harvard College in 1782-3 are so instructive on the point of agreement inter se and disagreement with the truth that I copy his separate results:

\section{Latitude of Harvard College.}

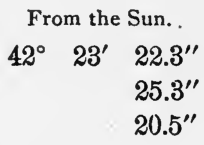

From Fixed Stars.
$42^{\circ} 23^{\prime} 25.1^{\prime \prime}$
$22.9^{\prime \prime}$
$34.1^{\prime \prime}$
$28.7^{\prime \prime}$
$36.5^{\prime \prime}$
$24.2^{\prime \prime}$
$28.6^{\prime \prime}$

From the Pole Star.

$42^{\circ} 23^{\prime} 28.6^{\prime \prime}$

$27.7^{\prime \prime}$

The mean adopted was $42^{\circ} 23^{\prime} 28.5^{\prime \prime}$. By comparison with the latitude of the observatory this result is $64^{\prime \prime}$ too great, and yet the average deviation from the mean is only $3.6^{\prime \prime}$.

In $1825 \mathrm{Mr}$. R. T. Paine, perhaps the most skillful observer with the sextant in this country, if not in the world, found the value of the latitude of the Old State House, Boston, to be $42^{\circ} 20^{\prime} 30^{\prime \prime}$, a value which differed $118^{\prime \prime}$ from that given on page 297 of the Transactions of the American Academy, which was also the result of a sextant determination. In 1828-9 194 observations with sextant "Ramsden 1403 " gave $20^{\prime} 5 \% .8^{\prime \prime}$, and 390 observations with "Ramsden 1375 " gave $20^{\prime} 5 \% .9^{\prime \prime}$. Yet the mean of 442 observations between 1833 and 1873 , divided equally between northern and southern stars, gave $21^{\prime} 23^{\prime \prime}$, with a range between greatest and least for 37 dates amounting to only $7.5^{\prime \prime}$. This result is " "' different from the value derived by Borden in his Trigonometrical Survey of Massachusetts. It gives for the latitude of Harvard College $42^{\circ} 22^{\prime} 15^{\prime \prime}$, the true value being $22^{\prime}$ 48.6". It is, therefore, $34^{\prime \prime}$ in error, while the earlier value is $59^{\prime \prime}$ in error. Mr. Paine's subsequent observations for the latitude of the Unitarian Church in old Cambridge gave $46.7^{\prime \prime}$, or within $2^{\prime \prime}$ of the truth.

It is well known that there is in general a well defined difference between results derived with the sextant from observations of the sun 
and of fixed stars, though Mr. Paine always got substantially identical results. At Syracuse in $18 \% 0$ Professor Harkness found the latitude from Polaris \%.1" to be less than from the sun. Professor Hall found a difference of 24.7". Struve, in his survey of 'Turkey, found that Alpha Aquilae gave latitudes $13^{\prime \prime}$ too large, and that this correction sometimes ran as high as $30.7^{\prime \prime}$.

It is obvious from this brief discussion that there is danger of placing too high an estimate upon the accuracy of the ordinary sextant considered simply as an instrument of observation. It is hardly necessary to say that agreement of repeated readings on a given part of the limb is not necessarily an indication of accuracy. The errors which are usually introduced in the graduation of a sextant belong to a class known as periodic errors. They are formed by successive increments of very minute errors, which it is perhaps impossible to measure individually, but which, by 'continual additions, may, at a given point on the limb, amount to a quantity several times greater than the error of observation.

The data at hand for assigning a limit to the actual errors of observation with the sextant at sea, taking into account all the errors to which such observations are liable, are exceedingly meagre. For the present I limit myself to the following discussions :

(a) Scattered through the volumes of the Nautical Magazine will be found records of the determinations of the longitude of various stations, chiefly in the West India Islands, made by various British naval expeditions. The data required are in many cases wanting, but sufficient are available to furnish a fair estimate of the average range of error. The chronometers employed were rated at the Greenwich Observatory at the beginning of the voyage, and the observations for time at the terminal stations were made in the usual way with the sextant. They were probably made on shore, though I can find no definite statement to this effect. Evidently more than usual care was taken with the observations and reductions. It is probable also that a sufficient number of observations were made at each station to eliminate accidental errors in a large measure. 


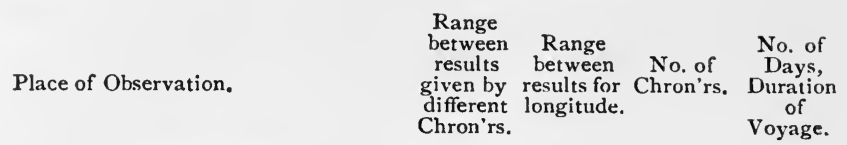

Hong Kong ......... Singapore, 1849-50....

Miles.

Miles.

" " ....... " 1852-53...

Funchal $\ldots \ldots \ldots \ldots \ldots \ldots \ldots \ldots \ldots \ldots . \quad 2.0$

Teneriffe........................ 0.2

Port Prayo..................... 3.2

St. Antonio..................... 9.0

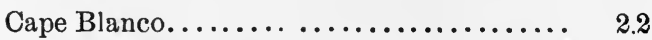

Cape Bojada.................... 1.8

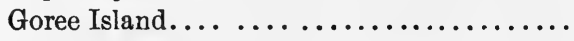

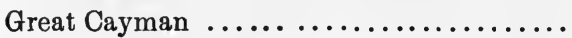

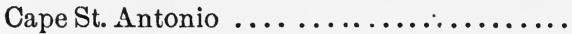

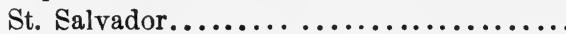

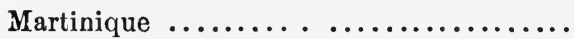

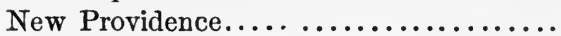

Guadaloupe..$\ldots \ldots \ldots \ldots \ldots \ldots \ldots \ldots$

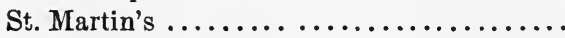

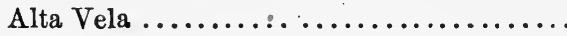

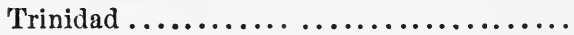

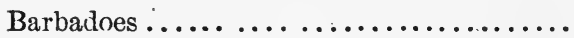

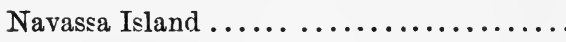

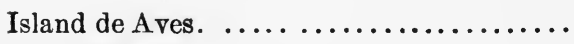

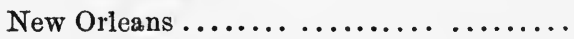

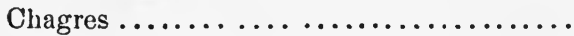

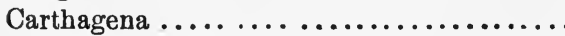

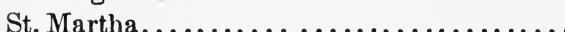

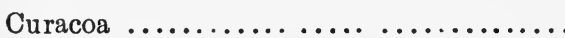

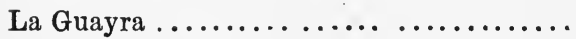

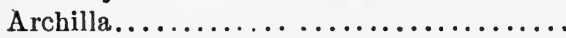

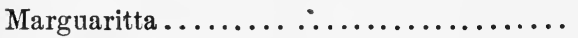

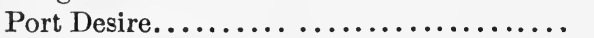

Port Farrin....................

Callao ........................ -

Valparaiso ...................... 6.0

Talcahuana ..................... 1.5

San Carlos ........................ 15.1

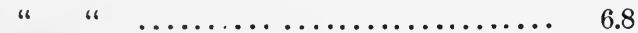

Panama ........................ -

Guayquil..................... -

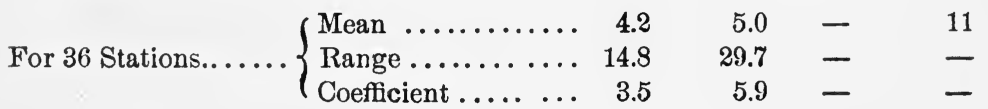

$\begin{array}{lll}10.0 & 5 & 18\end{array}$

$\begin{array}{lll}7.1 & 5 & 18\end{array}$

$1.5 \quad 10 \quad 11$

$0.9 \quad 11 \quad 3$

$\begin{array}{lll}1.3 & 11 & 10\end{array}$

$\begin{array}{lll}2.6 & 11 & 18\end{array}$

$\begin{array}{lll}2.0 & 6 & 3\end{array}$

$3.3 \quad 7 \quad 5$

$2.6-$

1.73

$2.3 \quad 3$

$18.8 \quad 6$

1.43

6.16

$4.3-$

$2.5-$

$3.7-$

$\begin{array}{lll}4.9 & 5 & 13\end{array}$

$\begin{array}{lll}1.6 & 3 & 6\end{array}$

$7.5-$

$2.2-$

$\begin{array}{lll}2.0 & 2 & 15\end{array}$

$\begin{array}{lll}1.7 & 2 & 3\end{array}$

8.326

$3.8-$

$2.4-$

$7.1-$

$\begin{array}{lll}1.2 & 7 & 19\end{array}$

\begin{tabular}{l}
$10 \quad 19$ \\
\hline
\end{tabular}

7.4

$\begin{array}{lll}1.4 & 13 & 17\end{array}$

$\begin{array}{lll}3.8 & 4 & 15\end{array}$

$\begin{array}{lll}31.6 & 20 & 27\end{array}$

$\begin{array}{lll}10.9 & 18 & 12\end{array}$

$2.7-2.8$

3.3 -

(1)

0

3

5


(b) During the spring and summer of 1880 Officer W. H. Bacon, of the Cunard steamer "Scythia," kindly undertook for me a series of systematic observations from which the relative errors could be determined with considerable certainty. A complete series for a single day consisted of five sights at intervals of fifteen minutes, about 8 o'clock in the morning, five sights in the neighborhood of 11 o'elock, and five sights at the corresponding hours in the afternoon. Observations were also made when the ship was in known positions as often as possible.

This series of observations has an exceptional value on account of the conscientious fidelity with which the programme was adhered to and of the skill with which they were made. The relative errors were determined by comparing each position with the mean of the series, the rate being determined both from the morning and afternoon observations and from the log.

The results obtained are found in the following table:

\begin{tabular}{|c|c|c|c|c|c|c|}
\hline Limits in Miles. & 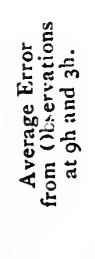 & 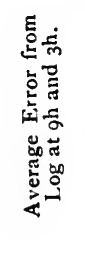 & 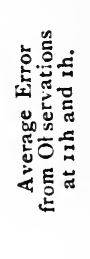 & 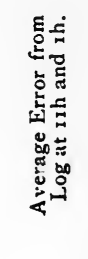 & 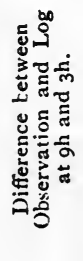 & 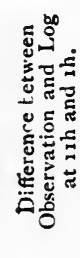 \\
\hline & $\begin{array}{c}\text { No } \\
\text { Cases. }\end{array}$ & $\begin{array}{l}\text { No } \\
\text { Cases. }\end{array}$ & $\begin{array}{c}\text { No. } \\
\text { Cases. }\end{array}$ & $\begin{array}{c}\text { No. } \\
\text { Cases. }\end{array}$ & $\begin{array}{c}\text { No. } \\
\text { Cases. }\end{array}$ & $\begin{array}{c}\text { No. } \\
\text { Cases. }\end{array}$ \\
\hline 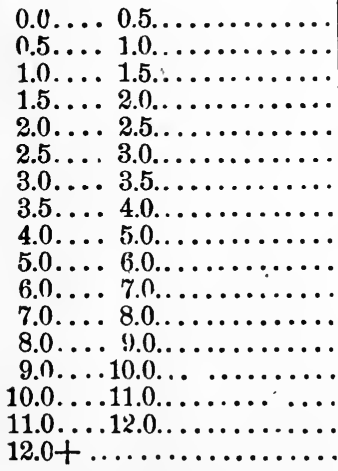 & $\begin{array}{l}1 \\
0 \\
8 \\
4 \\
6 \\
2 \\
2 \\
4 \\
1 \\
0 \\
0 \\
1 \\
2 \\
0 \\
0 \\
0 \\
1\end{array}$ & $\begin{array}{r}0 \\
6 \\
13 \\
5 \\
4 \\
1 \\
2 \\
1 \\
3 \\
0 \\
0 \\
1 \\
0 \\
1 \\
0 \\
0 \\
1\end{array}$ & $\begin{array}{l}0 \\
2 \\
3 \\
3 \\
6 \\
3 \\
6 \\
4 \\
6 \\
2 \\
2 \\
0 \\
1 \\
0 \\
0 \\
0 \\
0\end{array}$ & $\begin{array}{l}0 \\
3 \\
5 \\
3 \\
5 \\
4 \\
5 \\
5 \\
5 \\
1 \\
1 \\
1 \\
1 \\
0 \\
0 \\
0 \\
0\end{array}$ & $\begin{array}{l}7 \\
1 \\
3 \\
3 \\
2 \\
1 \\
7 \\
1 \\
4 \\
1 \\
2 \\
1 \\
0 \\
1 \\
1 \\
2 \\
0\end{array}$ & $\begin{array}{l}6 \\
2 \\
3 \\
2 \\
3 \\
0 \\
2 \\
2 \\
4 \\
5 \\
2 \\
1 \\
2 \\
2 \\
1 \\
1 \\
0\end{array}$ \\
\hline
\end{tabular}


It will be seen that the results from these two investigations do not materially differ from those previously found. In fact, whatever the line of investigation pursued, we reach substantially the same conclusion, viz. that the average error of a single observation at sea is not far from three miles, and that the average coefficient by which this number must be multiplied in order to provide for every contingency of danger is 3.5. 


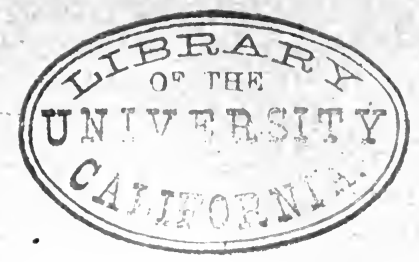

NAVAL INSTITUTE, ANNAPOLIS, MD.

JANUARY $12,1882$.

\section{THE COEFFICIENT OF SAFETY IN NAVIGATION.}

By Commander P. F. Harrington, U. S. N.

In the current volume of the Proceedings of the Naval Institute there appears an essay by Professor W. A. Rogers, of the Cambridge Observatory, on the Coefficient of Safety in Navigation, which is remarkable for the extent and thoroughness of its investigations, and valuable in the application of its results to the practice of navigation. The essay is based upon investigations to which the navy has not contributed, and it becomes important to consider the application of its conclusions to the ordinary course of navigation of men-of-war.

The coefficient of safety is defined as a number by which the average error of a ship's position should be multiplied in order to obtain the limit of possible error. If a ship be navigated in consideration of the limit so obtained, her safety is assured, so far as it depends upon an estimation of position. As determined by Professor Rogers, the coefficient is not strictly the ratio between the average error and the extreme error; but it may be so regarded in practice, upon the assumption that the least error in a series approaches nearly to zero.

In order to value the final effect upon the computed co-ordinates of a ship's position, the errors to which the data are liable may be classed and considered with regard to their influence in the computations and upon the estimated progress of a ship subsequent to the astronomical determination of her position. Those errors which affect the altitude as an element of the data, in observations at sea, are: first, instrumental errors, or those of the sextant; secondly, errors of observation; and, thirdly, errors of the tabulated dip and refraction. 
The constant errors of the sextant are those of excentricity and graduation; and there are others, of a variable nature, which are due to the surfaces of the index and shade glasses not being parallel, to the setting of the telescope in a plane inclined to that of the instrument, to small inclinations of the index and horizon glasses, to an increase of the apparent diameter of the sun arising from the feeble power of the telescope, and to the effects of changes in the temperature. No error can arise from a prismatic form of the horizon glass. These errors differ in value for different sextants and at different times in the same sextant, and the total amount may or may not be inconsiderable. On shore, they may be examined and the corrections partially ascertained. Professor Rogers finds, from a series of observations on shore, a value of $7.6^{\prime \prime}$ for the average error in latitude and of $1.1 \mathrm{~s}$ in longitude, and a value of the coefficient of four and seven tenths. In these observations the errors of the sextants were thoroughly investigated and the corrections were applied; but the results are open to the objection that they were obtained by a comparison with the mean of the series and not with a fixed value. The suggestion that the coefficient should be increased by three units for single observations at sea is not unreasonable; and from this we find the average liability to error at sea exceeding one minute of arc. It does not appear that the values reported are due entirely to the sextant and have reference to the altitudes of the bodies observed; but the character of the observations, of bodies on the meridian for latitude and near the prime vertical for longitude, justifies the assignment of the error to the sextant, since the error of the instrument entered directly into the altitude and was transmitted in its full amount to the computed latitude, or to the longitude with but little alteration, and since no other element conld be erroneous. other considerations, already stated, support the conclusion that the error of altitude at sea, due to the sextant alone, may exceed one minute.

The errors of observation include the inaccurate valuation of the index error, the personal error in the observation itself, the error of making the contact without the middle of the field of the telescope, and the special error of observation when the motion of the ship is considerable. The error arising from defective shade glasses may be avoided by using a shade cap over the eye-glass of the telescope. A screen of card board may be fitted over the eye-piece to shield the eye from the glare of rays, other than those passing through the 
telescope. The total value of the errors of observation is neglected, necessarily, at sea, nor does it appear how these and the sextant errors may be considered except by the use of a coefficient of safety.

The most serious error is that of the tabulated dip. As the ship rises and falls with the swell of the sea, it is difficult to fix the height of the observer's eye ; and, at moderate elevations, an error of four feet in the estimated height of the eye causes an error of about half a minute in the apparent altitude. Moreover, the dip is tabulated for a mean condition of the atmosphere. The path of a horizontal ray of light near the earth's surface varies greatly with the state of the atmosphere. From this cause the tabulated dip cannot be relied upon more closely than two minutes, when the eye is not elevated more than sixteen feet. The curvature of a ray of light in air at any point in its course depends upon the pressure, temperature, and rate of change of temperature; the third condition being in general the most important. When the temperatures of the water and air differ greatly, the variation of the apparent place of the sea horizon from its mean place becomes extraordinary. Variations of four minutes have been observed frequently, by the use of a dip sector or prismatic. sextant, in comparison with a common sextant, and larger values have been found. The apparent horizon is depressed below or elevated above its mean place, according as the sea is warmer or colder than the air. For example, a large increase in the dip may be expected when traversing the Gulf stream in cold weather. The extreme case of displacement in a downward direction is illustrated by the mirage, where rays of lights pass from objects above the horizon, obliquely at first towards the earth, through successive layers of air of rapidly decreasing density and refracting power, and subsequently upwards, through air of increasing density, to the eye of the observer. 'The inverted image of the distant object is thus formed, while another image in its erect position is seen through the medium of rays passing more directly to the eye of the observer. In the polar regions images of distant objects sometimes appear lying in the air. This occurs when there is an extreme refraction in the contrary direction to that which causes the mirage, the layers of air near the sea decreasing rapidly in density with an increasing altitude. The tabulated refraction, which affects the altitude, also becomes more uncertain as the altitude of the body decreases. These errors of dip and refraction may be partially compensated by attention to the corrections for pressure and temperature of the air. The tables, however, are not perfect, nor 
do they always agree. 'I'wo tables, now in general use, differ three minutes as to the amount of refraction near the horizon, for a mean height of the barometer and thermometer.

Some function of the algebraic sum of these errors affecting the altitude enters into every computation for position at sea, and the error in marking the time of an observation or of a comparison enters directly into every determination of longitude. What, then, is the probable average error of an apparent altitude taken under favorable circumstances at sea? Will it fall below two minutes? Or, rather, can the navigator feel assured that it is not greater? It may be said that these errors and others yet to be noted will offset each other generally to some extent; but by what test may this be known in practice, and what part of the uncertainty is removed?

With respect to the latitude, when it becomes an element of the data, it must be remembered that its accuracy depends, primarily, upon observations of the character already described, and, secondarily, upon the closeness with which the run of the ship is noted. The same is true of the longitude, whenever it enters as a part of the data in any observation off the meridian; and it will contain also the error in the assumed longitude of the place of rating, the error in the original determination of the chronometer correction, and the accumulated error of the rate; and some function of the algebraic sum of these will enter into the computation. If the longitude is sought, the computed value will contain directly the errors last enumerated, besides that resulting from the computation.

It has been shown by Professor Rogers that it is difficult to determine accurately, even with excellent instruments and under the most favorable circumstances, the geographical position of a point on the earth's surface. The values of the coefficient, obtained from series of observations on shore, will be received with surprise, but. they must be accepted as true. What degree of dependence then shall be placed upon the result of a single set of observations at sea, affected by all the errors enumerated and in an unknown direction? Is it probable that the naval officer, using the best instruments and exercising the greatest care and selection in observations, computations, and methods of navigation, reduces the average and extreme errors of position to exceptionally small values? It may be asserted that the observations of naval officers are particularly accurate, but that is all that can be affirmed; and that the true position of a ship at sea is ever obtained from astronomical sources is exceedingly doubtful. 
Formulas and tables, by which the effect of the errors referred to may be considered, will be found in any good work on Navigation, and there are many practical methods of reaching the same end; but it may be interesting to notice, briefly, some rules by the observance of which the errors themselves may be reduced in amount and the general accuracy of the determinations may be improved.

Attention should be paid first to the situation of chronometers on board ship, with respect to the motion of the ship and to the proximity of any particular magnetic influences. Extreme motion of the ship disturbs the vibration of the chronometer balance and produces a change of rate. The balance may acquire a magnetic polarity; and, in order to avoid an error arising from this cause, the chronometers should be placed with the twelve hours mark of the face in the fore-and-aft line of the ship, and they should not be removed for any purpose. The rates should be found for the constant position of the chronometers. When proper precautions have been observed to avoid these disturbing agents and also the danger of rude shocks, it is conceded that variations in the rate are caused almost entirely by changes of temperature. It is desirable, therefore, to guard against sudden and extreme changes, and, whenever practicable, to provide a place of uniform temperature. On board ship this is almost impossible, and the navigator must rely. upon a close study of the chronometer and thermometer and of the law which connects their motions. During the progress of a cruise there will be found a gradual acceleration of the chronometer rate, which is independent of the effect of temperature. This is due to the thickening of the oil, which diminishes the amplitude of the vibrations of the balance. The amount of this change is peculiar to to each chronometer, and can be found only by experiment. Chronometers for the use of the navy are issued from the Naval Observatory at Washington, and are accompanied by a list of rates for different mean temperatures, found by actual trial and record.- With this list before him the navigator will be able to anticipate in an approximate degree the changes of rates, by attending to the daily temperatures of the chronometer room and to the record of comparisons. Every chronometer has its own law of change; and, further, the alteration of rate is not contemporaneous with but follows at different periods the changes of temperature. If this important duty of studying the character of each chronometer is neglected, a belt of possible error in longitude results from the average daily error and coefficient 
of safety for chronometers. The average daily error is $\pm 0.72 \mathrm{~s}$, and the value of the coefficient three units and two tenths. These quantities appear very large, but they are deduced from extensive and comprehensive examinations of chronometers; by a course of computation which offers no ground of objection.

The error and rate of a chronometer should be found from transit observations, or from equal altitudes of the same body when on opposite sides of the meridian. The whole error of longitude of the point of observation will enter into the chronometer error; but the rate may be closely determined by these methods, though the latitude and longitude are known only to an approximate degree. When such observations are impossible, the error may be found from single altitudes of the same body, on opposite sides of the meridian and near the same altitude, the mean of the results being adopted; and the rate from single observations of the same body, provided the conditions of atmosphere, altitude, and azimuth are not very different upon the two occasions. The error cannot be determined correctly from single observations of a body off the meridian. It seems unnecessary to argue that the sea horizon should not be employed in this work.

At sea, if the azimuth, or true bearing, of the body observed is less than forty-five or greater than one hundred and thirty-five degrees, the latitude should be computed from the observed altitude and the longitude by account. 'The error in the latitude, which results from the errors of the data, decreases as the body approaches the meridian in azimuth, and, when the body is on the meridian, it depends upon and is equal to the error in altitude. It should be remembered, however, that the maximum altitude of the sun differs from the meridian altitude, when the motion of the sun in declination is most rapid and when the ship's rate of movement in latitude is large, by an amount which; in certain latitudes, may exceed one'minute. In the case of the moon, this difference may be much greater near the periods when the moon's declination becomes zero.

If the true bearing of the body is more than forty-five degrees and less than one hundred and thirty-five degrees from the meridian, the longitude should be the co-ordinate sought. When the body is on the prime vertical, a small error in the latitude is of no importance, and the error of altitude has its least effect, or, nearly, its amount converted into time. The error of the chronometer correction cannot be eliminated. 
When the declination of the sun and the latitude are nearly equal and of the same name, the method of equal altitudes of the sun for longitude is highly recommended. The altitudes may be observed very near noon; and, in connection with the meridian altitude, the latitude and longitude are found almost simultaneously. If equal altitudes are lost, by reason of passing clouds, Littrow's method is still available, and is equally simple in computation.

It is recommended in Raper's Navigation that, when the altitude of the body is sufficient, it should be observed both from the opposite point of the horizon and from that under it, by the common sextant. Half the difference of the readings should be the apparent zenith distance of the body, eliminating the dip and the errors of the instrument. This assumes that the dip is the same at opposite points of the horizon. The difficulty of this observation would probably cause erroneous results, but it is suggested for trial, in deference to the high authority cited.

Observations at night are very unreliable, from the obscurity of the horizon and the difficulty of reading the sextant. But, during twilight, observations may be made which will reduce the uncertainty of the ship's position. The local time may then be found accurately from altitudes of stars east and west of the meridian and having similar zenith distances and azimuths, and a very close value of the latitude from altitudes of stars upon or near the meridian north and south of the zenith.

It is an obvious consequence of the preceding statements that the computation of position at sea to seconds of arc is unnecessary, so far as the accuracy of results is concerned, and that it may produce an appearance of precision and correctness not inherent in the methods. Aside from this tendency to engender an unreasoning confidence in the results, the habit of close figuring is a valuable one; and the use of seconds, in this class of computations, accords nearly with the usual practice of employing units of an order one lower than that required. Attention to minute details is almost essential to good navigation; and such attention leads at once to a just discrimination as to the degree of computation necessary.

When approaching a coast, off which the depths of water and character of the bottom are well marked, the lead becomes an invaluable aid to navigation. A good sounding and a line of position, taken together, are almost as useful as a lighthouse to an intelligent navigator. The following method of navigation by the lead is described 
by Sir William 'Thomson. "Take a long slip of card, or stiff paper, and mark along one edge of it points at successive distances from one another, equal, according to the scale of the chart, to the actual distances estimated as having been run by the ship in the intervals between successive soundings. If the ship has run a straight course, the edge of the card must be straight, but if there has been any change of direction in the course, the card must be cut with a corresponding deviation. At each of the points thus marked on the edge, write on the card the depth and character of the bottom found by the lead. 'Then place the card on the chart, and slip it about until you find an agreement between the soundings marked on the chart and the series written on the card. The slight ups and downs of the bottom, even if they be no more than to produce differences of five or six fathoms in depths of, say, from five-and-thirty to fifty fathoms, interpreted with aid from the character of the bottom brought up, give, when this method is practiced with sufficient assiduity, an admirably satisfactory certainty as to the course ,over which the ship has passed."

The errors incident to the progress of a ship must now be considered. Imperfect steering, unknown or incorrectly estimated currents and leeway, and errors in the compass deviations, generally result in some wandering from the given course. The distance sailed is not accurately known, nor is it likely, in the absence of means of finding the set and drift of the current at all times, that the run of the ship can ever be implicitly relied upon. 'From the Dutchman's log to the patent log, the instruments have all failed to record exactly the progress of the ship. Napier's pressure log and Hogg's speed indicator show the rate of speed at any instant with accuracy ; but for purposes of navigation we must look to improvements in those instruments which measure the total distance run by the ship, rather than to an indicator of the momentary speed. It is possible, however, that the pressure log, or the speed indicator, may be made to record continuously the rate of speed, by a mechanism similar to that of a selfregistering tide-gauge, forming a speed curve which would present the rate at any instant and, by simple measurements, the distance run, to a high degree of accuracy. In further consideration of the coefficient of safety, it may be assumed that the average error in the course is one quarter of a point, and that of the distance one twentieth of the run by log. It is difficult to state the possible range of error from these causes; but every naval officer can recall occasions 
when the place of the ship by account, after a run of a hundred miles, could not be depended upon within twenty miles in any direction, although good observations had been obtained at the beginning of the run. Yet this uncertainty corresponds to an error of one point in the course, or of one mile in a distance of five. Fortunately, in most instances, as in gales or known currents, the uncertainty becomes apparent and induces additional caution.

Of the large number of wrecks from preventable causes, and particularly of new iron or composite ships, the loss of a considerable per centum is caused by compass errors, such as unknown deviation due to change in the magnetic condition of the ship, to a change in magnetic latitude, to neglect of the heeling error, and to a change of course in high latitudes after the ship has sailed on one course for a long time. The causes of compass deviations and the character and degree of their changes are now well understood; and the losses from compass errors might be assigned justly to that class which includes ignorance or incompetence of the persons in charge of the vessels. The accomplished navigator foresees these subtle changes, understands their amount and effect, and provides the correction or remedy. The ignorant navigator very often makes a good guess, and sometimes makes a bad one and runs his ship by it into danger. But it cannot be doubted that a majority of vessels of the class here referred to, and many others, would have avoided disaster by the use of a coefficient of safety.

The erroneous position of the coast-line upon a chart may be considered, with regard to an approaching vessel, as represented by an equal error in the position of the ressel and in the opposite direction. For example, if a coast is five miles in longitude eastward of its place as represented on the chart, it is relatively the same as if the ship's actual place is five miles in longitude westward of its computed position by chronometer. In effect, the error in a coast-line may be dealt with as an error in the ship's position, and it thus becomes connected with the value of the coefficient of safety. The determination of longitudes by electric telegraph, by Lieut. Commanders F. M. Green and C. H. Davis, under the direction of the Bureau of Navigation, will be of incalculable value to the commerce of the world, in multiplying points of reference for chronometer errors and in the correction of charts.

Considering all the various sources of error, the average error of the ship's position at sea, as found from a single astronomical observa- 
tion, is required, and also the arerage hourly increase in this quantity due to causes operating subsequent to the astronomical determination. The application of a coefficient will then show upon a chart the circle of possible error; and, in approaching or passing a danger, the course of the ship should be laid from that part of the circle nearest to the danger, and pursued more particularly as the character of the soundings, currents, and absence of lights, render uncertain the proximity of the danger. The extreme errors are most difficult to ascertain at sea, from the want of a true standard to which to refer the computed positions, at the times these errors are likely to occur. It seems, therefore, the best course to adopt a value of the coefficient, say of four units, based upon the discussions of Professor Rogers, and to approximate to the amount of the average error. Every navigator may find a value of this error; first, in the manner indicated at the close of the essay, and, more accurately, by a comparison of computed positions with those found simultaneously with the observations, by cross bearings, or by horizontal angles by sextant between three points when passing well established landmarks. These comparisons should be obtained under all possible conditions, of atmosphere, of height of the eye, of altitude and azimuth of the body, and of motion of the ship. When a lighthouse or other good landmark is first sighted in the course of a voyage, its correct maynetic bearing and distance should be carefully determined and compared with the computed or chart bearing and distance, and in this manner the error in position at the end of a run may be found. For example, if a known point of land is seen at a true distance of twenty miles upon a magnetic bearing which differs one point from the chart bearing (corrected for deviation but not for variation), the error of position is not less than three and nine-tenths miles. If the bearings coincide, the computed distance may be in error, and the amount of the error may be ascertained frequently by attention to the progress of the ship and the change in the bearing of the object. A table of average errors could then be formed, in which the classification should regard mean altitudes, latitudes, height of the observer's eye, and variations of the atmosphere; and such results would be very useful, if the work be conducted systematically and reported in detail. Observations when at anchor in a roadstead, where there is a large arc of sea horizon visible, ought not to be included in such an investigation, as the nearness of the land will modify the condition of the atmosphere, and as the circumstances are different in other respects from 
those desired. Even in a roadstead, a series of observations would produce interesting results, and would probably lead most people to join Professor Rogers, in the respect he feels for the judgment of that sea-captain, who placed the average error of a ship's position at five miles.

The use of the coefficient is not very dissimilar to the best characteristic of Sumner's method, in connection with a single line of position. The prudent navigator assumes that his ship is not at the point on the chart indicated by the computed latitude and longitude, nor even upon the line of position, but at any point within a belt formed by drawing parallels on each side of the line of position at such a distance as to include all the probable errors of altitude, chronometer, etc., incident to the particular circumstances of his observation and progress.

The essay of Professor Rogers will be read with profound interest by naval officers. It indicates a field of investigation in which the efforts of naval officers may be usefully exerted. Its practical conclusions and warning ought to be impressed upon every man who is permitted to lay a vessel's course. The term Coefficient of Safety in Navigation should be received into the vocabulary of nautical phrases, to be associated in the mind of the navigator with the errors which he must estimate and correct, and to become a momentary element in that watchfulness which is the price, though not the assurance, of safety upon the sea. 




\section{U.C. BERKELEY LIBRARIES}

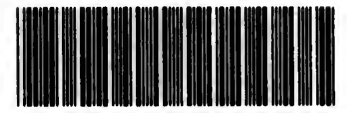

C035649333 
